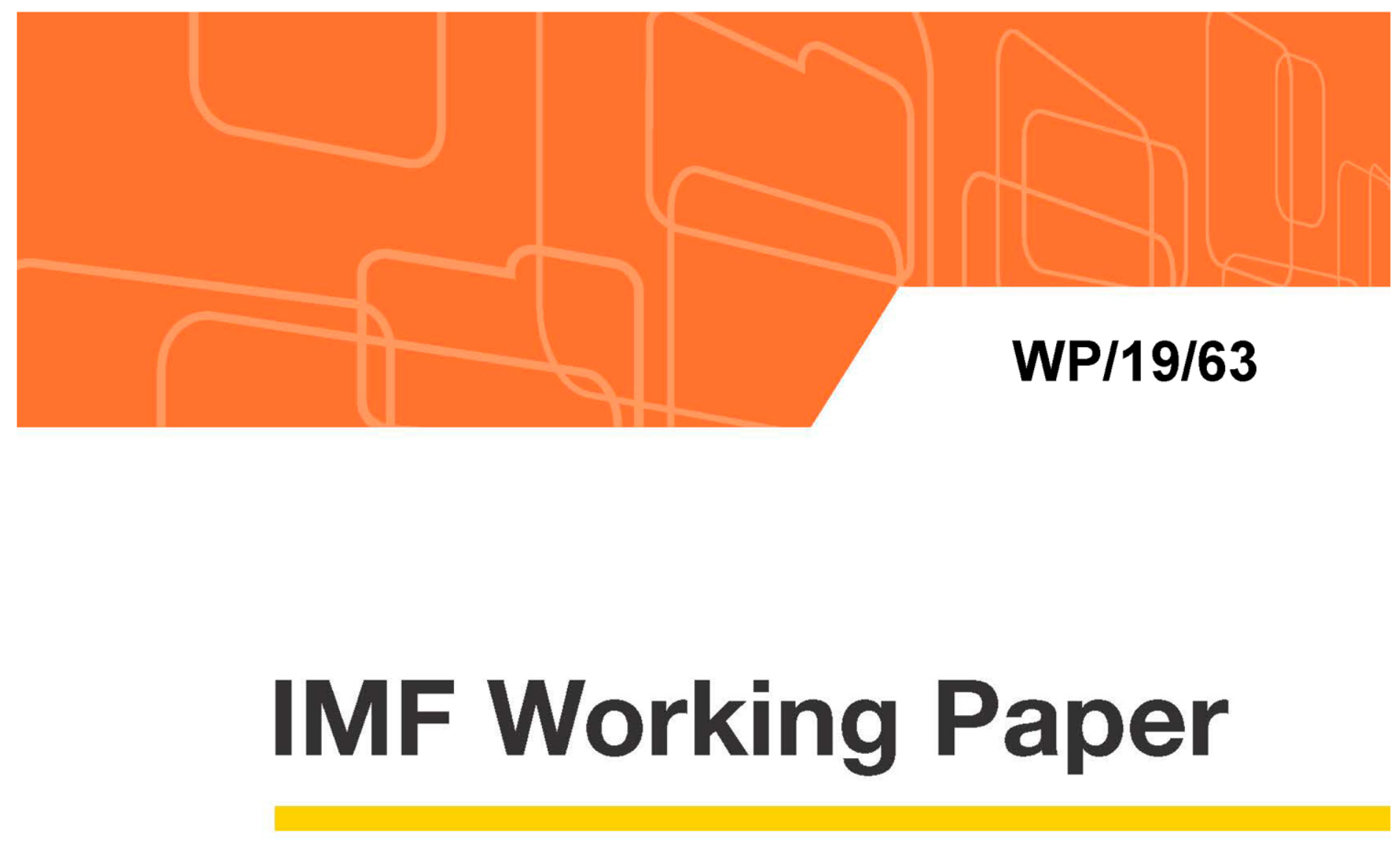

Fundamental and Speculative Demands for Housing

by Weicheng Lian 


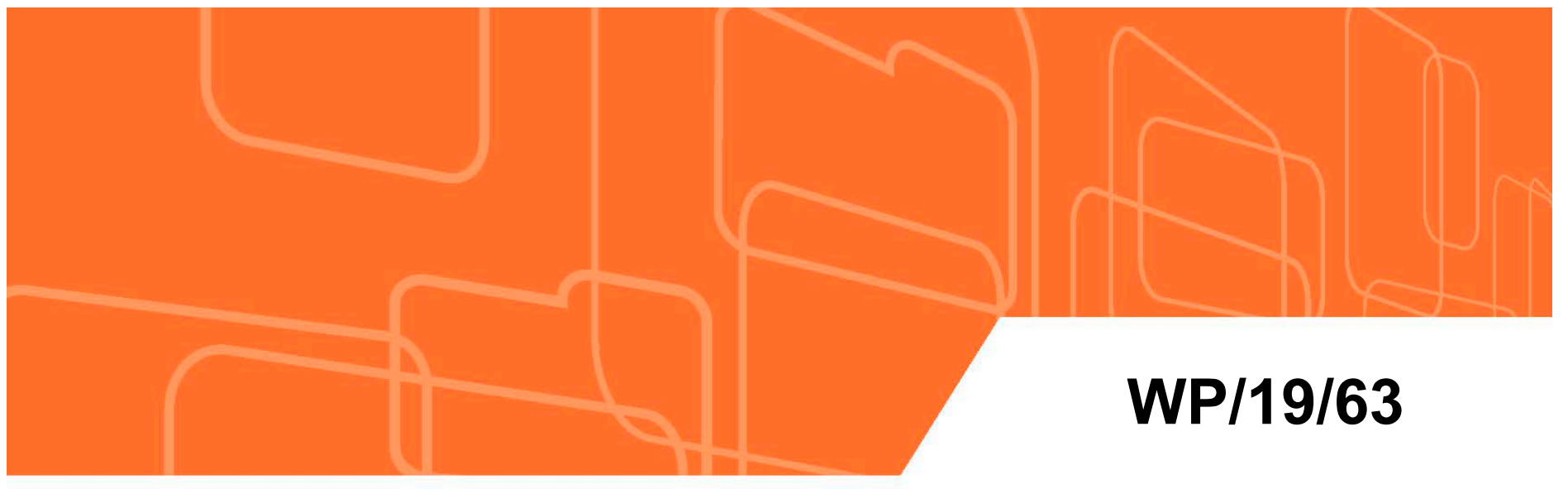

\section{IMF Working Paper}

Fundamental and Speculative Demands for Housing

by Weicheng Lian

I N T E R N A T I O N A L M O N E T A R Y F U N D 


\title{
Fundamental and Speculative Demands for Housing
}

\author{
By Weicheng Lian*
}

\begin{abstract}
This paper separates the roles of demand for housing services and belief about future house prices in a house price cycle, by utilizing a feature of user-cost-of-housing that it is sensitive to demand for housing services only. Optimality conditions of producing housing services determine user-cost-of-housing and the elasticity of substitution between land and structures in producing housing services. I find that the impact of demand for housing services on house prices is amplified by a small elasticity of substitution, and demand explained four fifths of the U.S. house price boom in the 2000 s.

JEL: E10, E32, G12, G40, R30, R31

Keywords: Asset Bubbles, Belief, Housing Cycles, Land Prices, Land Share
\end{abstract}

The house price cycle that peaked in 2006 in the United States is often referred to as a housing bubble, but it is challenging to quantify the size of the bubble. Kaplan, Mitman and Violante (2017) has estimated the price change to be caused mainly by a shift in belief about future house prices that was disconnected from fundamentals in the current period. Other studies have emphasized instead that shifts in demand for housing services were the dominant driver of the cycle (Iacoviello and Neri (2010); Liu, Wang and Zha (2013)). Behind the lack of consensus is the inability of existing approaches to separate the roles of belief about future house prices disconnected from today's fundamentals and demand for housing services in a house price cycle. This is an important gap in the macroeconomics literature, as a house price cycle can drive a business cycle and the optimal policy response to it depends on whether it is belief- or demand-driven. ${ }^{1}$

This paper separates demand and belief by utilizing a feature of user-cost-ofhousing that the two drivers have sharply different impact on it. The intuition is easy to see in a partial equilibrium setting in which today's house price is taken as given: a positive belief shift in the form of higher expected future prices reduces user-cost-of-housing today, whereas a positive demand shift drives it up. As I will show later, in a general equilibrium setting, this sharp difference in the response

* Research Department, International Monetary Fund, 70019 ST NW, Washington, DC 20431 (e-mail: wlian@imf.org). I would like to thank Oya Celasun, Lawrence J. Christiano, Giovanni Dell'Ariccia, Jesus Fernandez-Villaverde, Mikhail Golosov, Deniz Igan, Oleg Itskhoki, Nobuhiro Kiyotaki, Maria Soledad Martinez Peria, Jianjun Miao, Gian Maria Milesi-ferretti, Sohaib Shahid, and Valerie A. Ramey for comments. The views expressed in IMF Working Papers are those of the author and do not necessarily represent the views of the IMF, its Executive Board, or IMF management.

${ }^{1}$ It is relevant for issues such as whether monetary policy should lean against a house price boom, or the effectiveness of policy interventions to support house prices during the downturn of a cycle (Bernanke and Gertler (2001), Kahn (2009), Galí (2014), and Kaplan, Mitman and Violante (2017)). 
of user-cost-of-housing between the two types of drivers does not go away: usercost-of-housing is sensitive to demand only. Therefore, if user-cost-of-housing can be measured accurately, it provides useful information to separate demand and belief.

One challenge for separating the roles of demand and belief in a national house price cycle through user-cost-of-housing is that there is no consensus in the literature about how to determine it at the aggregate level. One approach is to use the CPI rent as a proxy (Favilukis, Ludvigson and Van Nieuwerburgh (2017); Kaplan, Mitman and Violante (2017)). However, the CPI rent is imputed based on a rental-equivalence approach, which is criticized by Prescott (1997) as being inconsistent with the principle that "the effective price of a commodity should be its cost to the household consuming it." Moreover, Gordon and Van Goethem (2004) argues that a difference in demographic characteristics between an average renter and an average homeowner can lead the rental-equivalence approach to have a bias in measuring user-cost-of-housing for owner-occupied properties. ${ }^{2}$ An alternative way is to construct user-cost-of-housing as the difference between house price today and the discounted value of expected house price in the next period. The challenge here is that there is no reliable measurement of house price expectations in the US economy at the national level.

I overcome these challenges by analyzing supply in the market of housing services. Under the assumption that the market for housing services is under perfect competition, the price of housing services (user-cost-of-housing) is the same as the cost of producing housing services, which further depends on housing services production function and input costs. I would determine the cost of structures based on the deflator of residential structures from the national income and product accounts (NIPA) and the historical trend of this deflator, under the assumption that the structure deflator trend is determined by the productivity differential between the construction sector and the rest of the economy. Aggregate usercost-of-housing is then equal to the cost of structures divided by the marginal productivity of structures in producing housing services.

To determine the marginal productivity of structures in producing housing services, it is important to decide how easily structures can substitute land to produce housing services. If the elasticity of substitution between land and structures in producing housing services is smaller, the marginal productivity of structures in producing housing services declines faster for a given increase in the ratio of structure quantity to land quantity.

I apply this approach of determining user-cost-of-housing to the housing cycle between 2000-2015 in the United States. Three data features suggest that there

\footnotetext{
${ }^{2}$ Díaz and Luengo-Prado (2008) develops a life-cycle model to show that the valuation of owneroccupied housing services is significantly different between a user cost approach and a rental-equivalence approach, due to tax treatment difference between rental and owner-occupied properties. Verbrugge (2008), and Garner and Verbrugge (2009) find that user-cost-of-housing is much more volatile than the CPI rent empirically, although their construction needs an assumption about expected future house prices.
} 
was a significant rise in user-cost-of-housing during the boom, which was associated with a strong decline in the marginal productivity of structures in producing housing services.

First, there was a strong boom in residential investment between 2001 and 2006. Residential investment as a share of GDP averaged 4.5 percent between 1995 and 2000, rising to an average of 5.7 percent between 2001 and 2006 (a 26 percent increase). This share averaged just 3.5 percent between 2013 and 2017.

Second, the land supply was inelastic in response to the housing boom. The growth of the aggregate quantity of residential land did not accelerate during this period. It declined from an annual average rate of 0.77 percent between 1995Q1 and 2001Q1 to 0.55 percent between 2001Q1 and 2007Q1 and 0.37 percent between 2013Q1 and 2016Q1. ${ }^{3}$

Third, it is difficult to substitute structures for land to produce housing services in the aggregate economy in the United States. Panel a of Figure 1 shows that the share of land in house value was volatile, fluctuating around an upward trend. Given land prices grew more rapidly than structure prices, this pattern indicates that the elasticity of substitution between land and structures is smaller than $1 .{ }^{4}$ Glaeser, Gyourko and Saks (2005) attributes this upward trend in land's share in house value to tighter zoning restrictions in the U.S. economy. Panel b shows a positive and strong correlation between the log ratio of land value to structure value and the $\log$ ratio of land price to structure price. As I will show later, under a plausible assumption that the ratio of price to user cost is stationary, the two log ratios are co-integrated and the elasticity of substitution between land and structures can be derived from the co-integration relationship coefficient. I estimate the elasticity of substitution in the United States to be around 0.2, which is close to the value used by Garriga, Manuelli and Peralta-Alva (2012).

[Figure 1 here]

These features suggest that the ratio of structure quantity to land quantity rose rapidly during the early 2000s, which implied a decline in the marginal productivity of structures in producing housing services. The decline was particularly strong as the elasticity of substitution between land and structures is small, which further implied a strong rise in user-cost-of-housing and a significant role of housing demand shocks in causing the house price boom-user-cost-of-housing is not sensitive to belief shocks. Although I describe such intuitions using a representative housing market, one can imagine that in a setting with multiple housing markets, tighter zoning restrictions in markets of better location can lead to a significantly faster decline in the marginal productivity of structures in producing

\footnotetext{
${ }^{3}$ The land quantities are computed based on land values and a land price index constructed by Davis and Heathcote (2007) - they control for the quality of land and have been extended by Morris Davis to 2016 Q1.

${ }^{4}$ I confirm this conjecture in Appendix $A 7$, where a quantitative exercise shows that if the elasticity of substitution is equal to 1 , the land share would have been much more stable during this period.
} 
quality-adjusted housing services after an increase in the ratio of structure quantity to land quantity, other things equal. In this paper, I use a representative national housing market and a small elasticity of substitution between land and structures to capture such effects.

I determine the roles of different types of shocks in the house price cycle in the 2000s by developing a general equilibrium model, which augments a standard overlapping generations model with a housing sector. I consider a land development process such that land supply endogenously responds to land prices. I use an aggregate housing services production function that has a constant-elasticityof-substitution (CES) form to capture the small elasticity of substitution between land and structures in producing housing services.

I set up the model in the following way to analyze the house price cycle in the 2000s: the model economy in 2000 is on a transition dynamics that starts from 1950, and receives four types of shocks between 2000 and 2015: housing demand shocks (which shift housing preferences of both current and future generations equally and permanently), belief shocks (which shift housing preference of future generations permanently), total factor productivity (TFP) shocks (which shift the productivity of producing non-housing goods), and shocks to structure prices. ${ }^{5}$ I include TFP shocks so that housing demand shocks do not capture conventional business cycle shocks. Shocks to structure prices help match usercost-of-structures.

The magnitude of the four shocks is chosen such that four aggregate variables in the model - output, structure prices, land prices, and the ratio of residential investment to output - are consistent with their data counterparts. Such a shock determination process helps the model to be consistent with user-cost-of-housing through matching structure costs and the marginal productivity of structures.

Two main findings are as follows. First, aggregate user-cost-of-housing was much more volatile than the CPI rent during the 2000s. The growth of aggregate user-cost-of-housing was much stronger than what was observed for the CPI rent during the boom, and the divergence between aggregate user-cost-of-housing and the CPI rent was largely reversed during the house price crash. ${ }^{6}$ This finding confirms quantitatively the intuition that a strong boom in residential investment, an inelastic supply of land, and a small elasticity of substitution between land and structures in producing housing services should imply a strong increase in aggregate user-cost-of-housing. ${ }^{7}$

Second, I find that four fifths of the house price increase during the 2000s was caused by demand for housing services. In particular, define the trend of house

\footnotetext{
${ }^{5}$ As I will elaborate later, I assume agents have perfect foresight. All the shocks have zero probability of occurrence. In each year between 2000 and 2015, the economy receives all four shocks.

${ }^{6}$ Studies that examine measurement errors in CPI include Moulton (1996), Boskin et al. (1998) and Lebow and Rudd (2003).

${ }^{7}$ Several previous studies show that a rental-equivalence approach may not capture user-cost-ofhousing accurately in the United States (Verbrugge (2008) and Garner and Verbrugge (2009)). A key difference between my paper and these studies is that I do not need to make any direct assumption about expectation of house prices in the next period.
} 
prices as the path of house prices if there were no shocks between 2000 and 2015, and assume that the house price was on the trend in 2000. The model suggests that house price was about 25 percent above the trend in 2006 and about 15 percent below it in 2011. Belief shocks contributed to only 5 percent above the trend in 2006 and the entire 15 percent deviation during the downturn. The second finding confirms quantitatively the intuition that user-cost-of-housing is not sensitive to belief shocks, and its strong rise during the boom, as described in the first finding, implies an important role of demand for housing services in causing the boom.

The second finding is different from those of Liu, Wang and Zha (2013) and Kaplan, Mitman and Violante (2017) - the former attributes almost the entire land price cycle during the 2000s to housing demand shocks, and the latter to belief shocks. One obvious reason to explain why we reach different findings is that I consider the two shocks simultaneously. Moreover, Liu, Wang and Zha (2013) and Kaplan, Mitman and Violante (2017) do not consider the price and quantity of residential investment.

To show that considering residential investment dynamics plays a key role in my results and also to suggest a robustness of the two findings to a larger elasticity of substitution between land and structures, I show that even if the elasticity of substitution between land and structures were 1, belief shocks would only account for around half of the house price boom during the 2000s, with the rest attributed to housing demand shocks and shocks to structure prices. In this case, user-costof-housing would still be significantly more volatile than the CPI rent during the 2000s. ${ }^{8}$

A smaller elasticity of substitution between land and structures further reduces the role of belief shocks in driving house prices in two ways. First, for an increase in residential-investment-to-GDP ratio, for instance, it implies a stronger rise in user-cost-of-housing and a larger increase in demand for housing services accordingly. Second, it amplifies the impact of housing demand shocks on house prices by making it more difficult to meet the increase in current and future demands for housing services through structures. The resulted stronger demand for land in current and future periods drive up land prices today immediately.

These mechanisms suggest that the form of belief shocks should not play a role in my findings. To illustrate this, I use shocks to expectation about longterm growth to replace housing preference shocks to future generations to capture belief shocks, and show that the two findings (volatile user-cost-of-housing and a dominant role of demand in the price boom) are not sensitive to this change. ${ }^{9}$

\footnotetext{
${ }^{8}$ This finding suggests that significant measurement errors of the CPI rent in capturing aggregate user-cost-of-housing could be more general than just a low elasticity of substitution between land and structures in producing housing services or tight zoning restrictions. As exploring this issue fully requires a more careful modeling of the segmentation between rental and property markets and the difference between renters and homeowners, I leave it for future research.

${ }^{9}$ Kiyotaki, Michaelides and Nikolov (2011) considers shocks to expectation about long-term productivity growth. The current model has a simple transmission from growth shocks to demand for housing services. In a more complex model, such shocks may be an underlying drive of demand for housing
} 
Related Literature This paper contributes to the strand of literature on housing cycles. Davis and Van Nieuwerburgh (2015) and Piazzesi and Schneider (2016) provide reviews on it. There is an emerging consensus that a house price cycle can be an independent source of a business cycle - it does not just reflect conventional business cycle shocks. A large number of quantitative studies try to understand what caused the strong housing cycle in the United States in the 2000s. ${ }^{10}$ Among them, only a few seek to decompose the overall house price cycle to understand the contribution of different shocks. This paper is closely related to Iacoviello and Neri (2010) and Liu, Wang and Zha (2013), both of which find a dominant role of housing demand shocks in causing the house price boom. The main difference between our papers is that I determine housing demand shocks based on user-cost-of-housing, and consider belief shocks as an additional force driving a house price cycle.

By exploring the role of belief shocks in causing house price cycles, this paper is related to a large literature on asset bubbles. ${ }^{11}$ Mayer (2011) provides a survey of research on housing bubbles and concludes that "existing research does not yet provide a crisp definition of how to define a housing bubble nor does it allow researchers to predict where or when bubbles can occur". I contribute to this strand of literature by developing a structural approach to determine the fundamental value of house price in real time - I capture in a parsimonious model a large set of factors that previous studies have argued as drivers of house prices. ${ }^{12}$

By showing that the elasticity of substitution between land and structures in producing housing services in the US economy at the national level is smaller than 1 and exploring its implication for house price cycles, this paper is connected with recent studies that explore macroeconomic implications of zoning restrictions (Glaeser, Gyourko and Saks (2005); Hsieh and Moretti (2015); Glaeser and Gyourko (2018)). The connection between a limited elasticity of substitution between land and structures and zoning restrictions comes from the fact that land prices have risen faster than structure prices, which should induce a substitution of structures for land to provide housing services. A smaller-than-1 elasticity of substitution between land and structures captures the force causing land's share

${ }^{10}$ An incomplete list includes Iacoviello and Neri (2010), Kiyotaki, Michaelides and Nikolov (2011), Garriga, Manuelli and Peralta-Alva (2012), Liu, Wang and Zha (2013), Justiniano, Primiceri and Tambalotti (2015), Landvoigt, Piazzesi and Schneider (2015), Burnside, Eichenbaum and Rebelo (2016), Favilukis, Ludvigson and Van Nieuwerburgh (2017), and Kaplan, Mitman and Violante (2017), among others.

${ }^{11}$ Recent contributions on this subject include Shiller (2000),Scheinkman and Xiong (2003), Akerlof and Shiller (2010), Glaeser (2013) Cheng, Raina and Xiong (2014), Galí (2014), Glaeser and Nathanson (2015), Nathanson and Zwick (2017), Kaplan, Mitman and Violante (2017), Barberis et al. (2018), and Greenwood, Shleifer and You (2018).

${ }^{12}$ I consider (a) demographic change, (b) productivity growth, which drives expected future rent growth, (c) the short-run and the long-run supply elasticity of land and structures, (d) the elasticity of substitution between land and structures in producing housing services, and (e) a set of "fundamental" shocks (TFP, shocks to structure prices, and housing demand shocks), building upon a large strand of literature that examine the relationship between house prices and fundamental factors (Mankiw and Weil (1989);Capozza and Helsley (1989);Davis and Heathcote (2005);Glaeser, Gyourko and Saks (2005);Kiyotaki, Michaelides and Nikolov (2011);Iacoviello and Neri (2010);Liu, Wang and Zha (2013))
} 
in house value to rise over time, and Glaeser, Gyourko and Saks (2005) attributes it to zoning restrictions. Hsieh and Moretti (2015) argues that zoning restrictions cause mis-allocation of labor across regions, which hampers long-run growth in the United States. ${ }^{13}$ I show later that under the same shocks during the 2000s, land's share in house value would have become much less volatile if the elasticity of substitution between land and structures is 1 .

The rest of the paper is organized as follows. Section I describes the optimality conditions of producing housing services that are used to reveal the key mechanisms of this paper. Section II presents the general equilibrium model. Section III describes the quantitative exercises and presents their results. Section IV provides robustness tests and discusses how to detect belief-driven house price cycles. Section V concludes.

\section{Optimality Conditions of Producing Housing Services}

This section considers an optimization problem for a representative housing service producer, and shows that (a) user-cost-of-housing is equal to cost-ofstructures divided by the marginal productivity of residential structures in producing housing services and (b) the ratio of land value to structure value and the ratio of land price to structure price are co-integrated, if the ratio of price to user cost is stationary for both land and structures.

To begin with, consider a representative housing services producer who sells housing services at price $d_{t}^{H}$. The firm maximizes its present value:

$$
\begin{array}{r}
\max _{\left\{S_{t+s}, L_{t+s}\right\}_{s=0}^{\infty}} \frac{1}{\prod_{j=0}^{s-1} R_{t+j}}\left[d_{t+s} H\left(S_{t+s}, L_{t+s}\right)-p_{t+s}^{L}\left(L_{t+s}-L_{t+s-1}\right)+\right. \\
p_{t+s}^{S}\left(S_{t+s}-\left(1-\delta_{S}\right) S_{t+s-1}\right)
\end{array}
$$

where $R_{t}$ is the interest rate, $S_{t}$ is the structure quantity, $L_{t}$ is the land quantity, $P_{t}^{L}$ is the land price, and $P_{t}^{S}$ is the structure price in period $t$. The housing service production function has a constant-elasticity-of-substitution (CES) form:

$$
H\left(S_{t}, L_{t}\right)=\left(\phi S_{t}^{1-\frac{1}{\rho}}+(1-\phi) L_{t}^{1-\frac{1}{\rho}}\right)^{\frac{\rho}{\rho-1}} .
$$

The first-order conditions of producing housing services with respect to land and structure quantities are as follows:

$$
\begin{aligned}
& d_{t} \frac{\partial H\left(S_{t}, L_{t}\right)}{\partial S_{t}}=d_{t}^{S}, \\
& d_{t} \frac{\partial H\left(S_{t}, L_{t}\right)}{\partial L_{t}}=d_{t}^{L}
\end{aligned}
$$

\footnotetext{
${ }^{13}$ Davis, Fisher and Whited (2014) shows that an upward trend of land prices is an important force behind agglomeration and long-run growth in the United States, but does not consider zoning restrictions.
} 
where $\frac{\partial H\left(S_{t}, L_{t}\right)}{\partial S_{t}}=\phi\left(\frac{H_{t}}{S_{t}}\right)^{\frac{1}{\rho}}$ and $\frac{\partial H\left(S_{t}, L_{t}\right)}{\partial L_{t}}=\phi\left(\frac{H_{t}}{L_{t}}\right)^{\frac{1}{\rho}}$. I refer to $d_{t}^{S}=P_{t}^{S}-\frac{\left(1-\delta^{S}\right) P_{t+1}^{S}}{R_{t}}$ and $d_{t}^{L}=P_{t}^{L}-\frac{P_{t+1}^{L}}{R_{t}}$ as costs of structures and land.

It is easy to prove Lemma 1 and 2 based on these first-order conditions.

Lemma $1 \ln \left(d_{t 1}\right)-\ln \left(d_{t 0}\right)=\ln \left(d_{t 1}^{S}\right)-\ln \left(d_{t 0}^{S}\right)+\frac{1}{\rho}\left(\ln \left(\frac{S_{t 1}}{H_{t 1}}\right)-\ln \left(\frac{S_{t 0}}{H_{t 0}}\right)\right)$

The relationship characterized by Lemma 1 allows for calculating user-cost-ofhousing without making an assumption about expected future house prices.

Lemma 1 reveals the role of the elasticity of substitution between land and structures in the inference of user-cost-of-housing: the smaller the elasticity of substitution between land and structures $\rho$, the larger the change in user-cost-ofhousing for the same change in the ratio of structure quantity to housing services quantity.

Lemma 2 shows that $\ln \left(\frac{P_{t}^{L} L_{t}}{P_{t}^{S} S_{t}}\right)$ and $\ln \left(\frac{P_{t}^{L}}{P_{t}^{S}}\right)$ are cointegrated, if $\ln \left(\frac{P_{t}^{L}}{d_{t}^{L}}\right)$ and $\ln \left(\frac{P_{t}^{S}}{d_{t}^{S}}\right)$ are stationary.

Lemma $2 \ln \left(\frac{P_{t}^{L} L_{t}}{P_{t}^{S} S_{t}}\right)=-\rho \ln \left(\frac{\phi}{1-\phi}\right)+(1-\rho) \ln \left(\frac{P_{t}^{L}}{P_{t}^{S}}\right)+\rho\left(\ln \left(\frac{P_{t}^{L}}{d_{t}^{L}}\right)-\ln \left(\frac{P_{t}^{S}}{d_{t}^{S}}\right)\right)$

Using developed land and structure value and price indexes revised from similar indexes constructed by Davis and Heathcote (2007) (Appendix A2 explains the revision), which are available between 1930-2015, I conduct Dicky-Fuller tests for $\ln \left(\frac{P_{t}^{L} L_{t}}{P_{t}^{S} S_{t}}\right)$ and $\ln \left(\frac{P_{t}^{L}}{P_{t}^{S}}\right)$. The results suggest that both contain unit roots. I then conduct the Engle-Granger two-step cointegration test for $\ln \left(\frac{P_{t}^{L} L_{t}}{P_{t}^{S} S_{t}}\right)$ and $\ln \left(\frac{P_{t}^{L}}{P_{t}^{S}}\right)$ and obtain the following relationship:

$$
\ln \left(\frac{P_{t}^{L} L_{t}}{P_{t}^{S} S_{t}}\right)=-1.653^{* * *}+0.752^{* * *} \ln \left(\frac{P_{t}^{L}}{P_{t}^{S}}\right)+\epsilon_{t} .
$$

Therefore, the aggregate elasticity of substitution between land and structures $\rho$ is equal to $0.248 .^{14}$

\section{The General Equilibrium Model}

This section develops the general equilibrium model, in which housing demand shocks and belief shocks are two key drivers of house price cycles. I augment

\footnotetext{
${ }^{14}$ Using the raw land price and quantity index provided by Davis and Heathcote (2007) between 1930 and 2000, and using the same approach to estimate the elasticity of substitution between land and structures, I get its value as 0.204 . I get higher values of 0.419 and 0.542 if I use the other two raw land price and value indexes constructed by them, which cover the period from 1975Q1 to 2016Q1. However, given the land price and value indexes are constructed through a residual approach, i.e., land value is defined as the difference between house value and residential fixed asset value, and land price appreciation is defined as the difference between house price appreciation and structure price appreciation, a long time series should be preferred to determine the co-integration relationship. Moreover, no theory would suggest that the housing supply constraint is getting looser over time, and if anything, Glaeser, Gyourko and Saks (2005) argues that zoning restrictions have become more widespread nationwide and tighter in the coastal areas since the 1970 s than earlier decades.
} 
a standard overlapping generations growth model by considering an endogenous land development process, production of structures, and the provision of housing services from land and structures, with the production function taking a constantelasticity-of-substitution (CES) form.

Including these elements extends the current ways of modeling land and structures as two distinct inputs for producing housing services (Davis and Heathcote (2005); Kiyotaki, Michaelides and Nikolov (2011); Liu, Wang and Zha (2013); Favilukis, Ludvigson and Van Nieuwerburgh (2017); Kaplan, Mitman and Violante (2017) among others). Compared with previous studies, I do not restrict the elasticity of substitution between land and structures to be 1, and the supply of land responds endogenously to land prices.

\section{A. The Model Elements}

The model economy has two types of final goods: general consumption goods and housing services. General consumption goods (the numeraire) are produced

from capital $K_{t}$ and labor $N_{t}: Y_{t}=K_{t}^{\alpha}\left(Z_{t} N_{t}\right)^{1-\alpha}$, where $Z_{t}$ is the labor-augmenting productivity. Capital depreciates at a rate $\delta^{K}$ and is transformed from general consumption goods one for one. Labor is supplied by households inelastically.

A representative firm in the general consumption goods sector maximizes its profit in period t by choosing capital $K_{t}$ and labor $N_{t}$ :

$$
\max _{\left\{K_{t}, N_{t}\right\}}\left[K_{t}^{\alpha}\left(Z_{t} N_{t}\right)^{1-\alpha}-r_{t} K_{t}-w_{t} N_{t}\right]
$$

A continuum of land developers, with the total measure normalized to be 1 , uses the same land development technology: $A^{L} L_{t-1}^{-\gamma}\left(Y_{t}^{L}\right)^{\omega}$, where $A^{L}$ is a constant scaler, $L_{t-1}$ is aggregate land quantity at the end of the previous period, and $Y_{t}^{L}$ is general consumption goods used for land development in the current period. The short- and long-term elasticities of land supply are governed by $\omega$ and $\gamma$. $\omega \in(0,1)$ implies that land development has decreasing return to scale in the short run; $\gamma>0$ captures the idea that high-quality land is scarce and land of higher quality is developed first.

An individual land developer maximizes its profit by choosing general consumption goods used for development $Y_{t}^{L}$ :

$$
\pi^{L}\left(P_{t}^{L}, L_{t-1}\right)=\max _{\left\{Y_{t}^{L}\right\}}\left[P_{t}^{L} A^{L} L_{t-1}^{-\gamma}\left(Y_{t}^{L}\right)^{\omega}-Y_{t}^{L}\right]
$$

where $P_{t}^{L}$ is the price of developed land. The profit maximization is static, because even though land development creates negative externality on future aggregate land development productivity, individual land developers are too small to internalize the effects.

A representative mutual fund owns all land developers and does not internalize 
the externality of land development either. Its present value is

$$
V_{t}^{L}=\sum_{s=0}^{\infty} \frac{\pi^{L}\left(P_{t}^{L}, L_{t-1}\right)}{\prod_{j=0}^{s-1} R_{t+j}} .
$$

A representative firm produces housing services $H_{t}$ from structures $S_{t}$ and land $L_{t}$. The housing services production function has a constant-elasticity-ofsubstitution $(\mathrm{CES})$ form: $H\left(S_{t}, L_{t}\right)=\left(\phi S_{t}{ }^{1-\frac{1}{\rho}}+(1-\phi) L_{t}{ }^{1-\frac{1}{\rho}}\right)^{\frac{\rho}{\rho-1}}$. Residential structures depreciate at a rate $\delta^{S}$, and one unit of structures is converted from $P_{t}^{S}$ units of general consumption goods in period $t$, with $P_{t}^{S}$ changing over time. The firm maximizes its net present value by choosing the quantities of land and structures: $\left\{S_{t+s}, L_{t+s}\right\}_{\{s=0, \ldots,+\infty\}}$.

$$
\begin{array}{r}
(4) V_{t}^{H}=\max _{\left\{S_{t+s}, L_{t+s}\right\}_{s=0}^{+\infty}} \sum_{s=0}^{\infty} \frac{1}{\prod_{j=0}^{s-1}\left[d_{t+s} H\left(S_{t+s}, L_{t+s}\right)-P_{t+s}^{L}\left(L_{t+s}-L_{t+s-1}\right)\right.} \\
\left.-P_{t+s}^{S}\left(S_{t+s}-\left(1-\delta^{S}\right) S_{t+s-1}\right)\right]
\end{array}
$$

Overlapping generations of households live in the economy, with $n_{t}$ households born in period $t$. Households live for $T$ periods. A household of age a in period $t$ faces mortality risk $m_{t}^{t-a}$. There are no borrowing constraints, and there is a no Ponzi game condition, requiring the net worth $b_{t}^{t-T+1} \geq 0$ in the last period of life.

A household born in period $t$ maximizes its life-time utility:

$$
\begin{array}{r}
\max _{\left\{c_{t+a}^{t}, h_{t+a}^{t}, b_{t+a}^{t}\right\}_{a=0, \ldots, T-1}} \sum_{a=0}^{T-1} \beta^{a} \prod_{j=0}^{a-1}\left(1-m_{t+j}^{t}\right) u\left(c_{t+a}^{t}, h_{t+a}^{t} ; \phi_{t+a}^{t}\right) \\
\text { s.t. } c_{t+a}^{t}+d_{t+a} h_{t+a}^{t}+b_{t+a}^{t}=R_{t+a}^{t} b_{t+a-1}^{t}+w_{t+a} l^{a}+T_{t+a} \\
b_{t-1}^{t}=0, b_{t+T-1}^{t} \geq 0
\end{array}
$$

where $\beta$ is household discount rate; $m_{t+j}^{t}$ is mortality rate in period $t+j$ for a household born in period $t$ - I allow mortality rate to be time varying to capture its downward trend in the United States; $c_{t+a}^{t}, h_{t+a}^{t}$, and $\phi_{t+a}^{t}$ are general goods consumption, housing services, and the weight of general goods consumption in household utility in period $t+a$ for a household born in period $t$. For simplicity, the period utility function is of the logarithm form:

$$
u\left(c_{t}^{t-a}, h_{t}^{t-a} ; \phi_{t}^{t-a}\right)=\phi_{t}^{t-a} \ln \left(c_{t}^{t-a}\right)+\left(1-\phi_{t}^{t-a}\right) \ln \left(h_{t}^{t-a}\right) .
$$

$b_{t+a}^{t}$ is the net worth of household. $T_{t+a}$ is the government transfer and distributes net worth of households who pass away in period $t+a-1$ equally among survivors and the newborn in period $t+a$.

In the baseline case and a robustness test later, I consider five types of shocks: 
housing demand shocks $\left(\epsilon_{t}^{\phi}\right)$, belief shocks $\left(\epsilon_{t}^{B}\right)$, shocks to structure prices $\left(\epsilon_{t}^{P^{S}}\right)$, TFP shocks $\left(\epsilon_{t}^{Z}\right)$, and growth shocks $\left(\epsilon_{t}^{G}\right)$. They affect labor productivities $\left\{Z_{t}\right\}_{t=0, \ldots, \infty}$, structure prices $\left\{P_{t}^{S}\right\}_{t=0, \ldots, \infty}$ and household housing preferences $\left\{\phi_{t+k}^{t-a}\right\}_{k=0, \ldots, \infty ; a=0, \ldots, T-1}$ as follows:

$$
\begin{aligned}
\ln \left(Z_{t}\right) & =\ln \left(Z_{t-1}\right)+g_{t}^{Z}+v_{t}^{Z}, \\
g_{t}^{Z} & =g_{t-1}^{Z}+\epsilon_{t}^{G}, \\
v_{t}^{Z} & =\rho^{Z} v_{t-1}^{Z}+\epsilon_{t}^{Z}, \\
\ln \left(P_{t}^{S}\right) & =\ln \left(P_{t-1}^{S}\right)+g^{P^{S}}+\epsilon_{t}^{P^{S}}, \\
\phi_{t+s}^{t-a} & =\phi_{t+s-1}^{t-a-1}+\epsilon_{t}^{\phi}, \text { for } 0 \leq a \leq T-1 \text { and } 0 \leq s \leq T-a-1, \\
\phi_{t+k+j}^{t+k} & =\phi_{t+k+j-1}^{t+k-1}+\epsilon_{t}^{\phi}+\epsilon_{t}^{B}, \text { for } k>0 \text { and } 0 \leq j \leq T-1 .
\end{aligned}
$$

As the economy does not have a steady state balanced growth path when the elasticity of substitution between land and structures is different from 1 unless a special condition is satisfied (the proof is in Appendix A4), I assume that agents have perfect foresight, and these shocks have zero probability ex ante.

There are three remarks on the model design, before turning to the calibration of its parameters. First, I do not consider borrowing constraints explicitly. The assumption that households obtain housing services only from rental markets is equivalent to an alternative that they can borrow up to the discounted future value of their homes (Kiyotaki and Moore (1997)). Under a more general form of borrowing constraints, house price is a function of not only user-cost-of-housing but also the "shadow value" of borrowing constraints (Garriga, Manuelli and Peralta-Alva (2012)), which can make the computation of the model much more burdensome.

The computation of the current model without a general form of borrowing constraints is already challenging. To capture the house price cycle in the 2000s accurately, I will choose one period to be a year. Households live for 76 periods (i.e. 20-95). The computation of one equilibrium will involve 602 equations to solve 602 unknowns-Appendix $A 6$ provides detailed discussion. Choosing the magnitude of the shocks to match the data targets in each year further complicates the computation. As the key mechanism is not likely to be affected by explicitly modeling borrowing constraints, I leave the extension of the current model with a more general form of borrowing constraints for future research.

Second, I let land prices be endogenously determined but have structure prices exogenously given. Previous empirical studies find that fundamental factors affect house prices mainly through land prices (Davis and Heathcote (2007)). ${ }^{15}$ Data also suggest that land prices have been much more volatile than structure prices

\footnotetext{
${ }^{15}$ In contrast, Iacoviello and Neri (2010) makes structure price dynamics the core in their analysis of house price cycles. A limitation of the model of Iacoviello and Neri (2010) is that it cannot explain the dynamics of land price and quantity, which is a strength of the model in this paper.
} 
over housing cycles. ${ }^{16}$

Recent quantitative studies analyzing land price dynamics include Kiyotaki, Michaelides and Nikolov (2011) and Liu, Wang and Zha (2013). The model in this paper, relative to those models, is consistent with a broader set of empirical patterns about land prices, land quantities, and land shares in house value. ${ }^{17}$

Third, I do not model renting and owning choices separately. Glaeser and Gyourko (2007) highlights that it is more likely for rental properties to be in multi-family buildings. It seems important to consider a segmentation between the market of owner-occupied properties and the rental market, to understand the impact of demand for housing services on house prices. However, there is not a consensus in how to model this. Favilukis, Ludvigson and Van Nieuwerburgh (2017) considers borrowing constraints and excludes renting as a way of obtaining housing services. In contrast, Kiyotaki, Michaelides and Nikolov (2011) and Kaplan, Mitman and Violante (2017) allow households to get around borrowing constraints by renting a house, and assume that there is no friction in converting rental properties into owner-occupied properties or vice versa. I leave this extension for future research.

\section{B. Model Parameterization}

The model calibration is standard. One period corresponds to one year in the data. Table 1 lists all the parameters. I determine them independent of the house price cycle in the 2000s. Most come from the data directly; the rest are determined by ensuring that long-run housing trends in the model are consistent with their data counterparts.

Indexes of land and structure price and quantity that control for quality are used to construct data moments to determine model parameters. I construct such indexes by revising housing indexes created by Davis and Heathcote (2007) and extended by Morris Davis to 2016Q1. I do not use the housing indexes of Davis and Heathcote directly, because the cost of land development is part of land value in my model, and Davis and Heathcote treat it as part of residential structures in their index construction. ${ }^{18}$ In other words, Davis and Heathcote construct raw land indexes, and I need developed land indexes to calibrate my model. Figure A1 (see Appendix $A 2$ for the figure) suggests that the two indexes have almost the same time profile, and hence my results are not driven by the assumption used in the index construction - the details of the construction can be found in Appendix $A 2$.

\footnotetext{
${ }^{16}$ One can easily verify this using the quality-adjusted land and structure price indexes constructed by Davis and Heathcote (2007).

${ }^{17}$ Kiyotaki, Michaelides and Nikolov (2011) does not compare land prices and quantities in their model with the data counterparts. Liu, Wang and Zha (2013) excludes residential structures as an input into the production of housing services and hence cannot be used to study land share in house value. They also do not compare land quantities in their model with the data counterpart.

${ }^{18}$ Appendix $A 2$ explains the procedure I use to remove land development from residential structures. This procedure is similar in spirit to the way in which Davis and Heathcote remove broker fees from residential structures in constructing their index.
} 
The parameter governing the short-run land supply elasticity $\omega$ is equal to the share of general consumption goods in developed land value, based on individual land developers' optimization decisions. I use the information about the land development cost breakdown compiled by the National Association of Home Builders and get $\omega=0.497 .{ }^{19}$

The parameter governing the long-run land supply elasticity $\gamma$ is estimated based on the optimality conditions of residential land development. ${ }^{20}$ They imply that

$$
\ln \left(L_{t}-L_{t-1}\right)-\frac{\omega}{1-\omega} \ln \left(P_{t}^{L}\right)=\ln \left(\left(A^{L}\right)^{\frac{1}{1-\omega}} \omega^{\frac{\omega}{1-\omega}}\right)-\gamma \frac{\ln \left(L_{t-1}\right)}{1-\omega} \cdot{ }^{21}
$$

By plugging the value of $\omega=0.497$, I estimate that $\gamma$ is equal to 1.74 .

The depreciation rates are 3 percent for structures and 7.1 percent for capital, which are determined based on residential and nonresidential fixed asset tables compiled by the Bureau of Economic Analysis (BEA). ${ }^{22}$

Households live for 76 periods, from age 20 to age 95. Labor endowments are interpolated based on the life-cycle income profile of both male and female workers reported by Hanse (1993). ${ }^{23}$

The share of general consumption goods in utility $\phi_{t}^{t-a}$ is 0.856 , which is determined as the average share of non-housing consumption in total private consumption in the NIPA between 1950-2017. ${ }^{24}$

Three remaining parameters - the share of capital in general consumption goods production technology, the discount rate of households, and the share of structures in housing services production function - are chosen such that the ratio of nonresidential investment to the output of general consumption goods, the ratio of residential investment to the output of general consumption goods, and the share of land in the aggregate housing value in the model are the same as their data counterparts between 1950 and 2015 on average. As there is not a steady state balanced growth path in the model, I compute the averages by letting the model economy be in a transition dynamics between 1950 and $2015 .{ }^{25}$ The definition of

\footnotetext{
${ }^{19}$ This value corresponds to the average share in 2004 . The data presented in Tabe A3 seem to suggest that this share has been stable over time.

${ }^{20}$ The optimality conditions are: $\omega P_{t}^{L} A^{L} L_{t-1}^{-\gamma}\left(Y_{t}^{L}\right)^{\omega-1}=1$, and $L_{t}-L_{t-1}=P_{t}^{L} A^{L} L_{t-1}^{-\gamma}\left(Y_{t}^{L}\right)^{\omega}$.

${ }^{21}$ The intuition behind this relationship is that a higher land price $P_{t}^{L}$ or higher land development productivity in the form of less land being developed in the past (captured by $\left.\frac{-\gamma \ln \left(L_{t-1}\right)}{1-\omega}\right)$ ) can lead to more land developed today (captured by $L_{t}-L_{t-1}$ ).

${ }^{22}$ More precisely, the depreciation of 3 percent for residential structures is determined from the structure indices I construct, which excludes land development.

${ }^{23}$ The endowments by 5 -year age group are $0.7500,1.0150,1.06750,1.12000,1.12375,1.1275,1.10375$, 1.0800 , and 0.9275 between age 25 and 60 . For simplicity, the labor endowment after age 60 is set as zero. I do not expect that introducing social security and income tax affects my results, as they lead to within-economy reallocation of resources, which should not interfere with the mechanism of this paper.

${ }^{24} \mathrm{An}$ often-used value in the literature is 0.8 (See $\mathrm{Li}$ and Yao (2007), among others). Kiyotaki, Michaelides and Nikolov (2011) chooses 0.76, to include other durable goods in housing services. My value is higher as energy and utilities are excluded from housing services.

${ }^{25}$ In Appendix $A 4$, I prove that when the elasticity of substitution between land and structures in
} 
the transition dynamics can be found in Appendix A5.

The model does a good job in explaining long-term trends of housing variables. In Appendix A7, I show that the model is consistent with upward trends of land's share in house value and the ratio of house value to GDP, a downward trend in the ratio of residential investment to GDP, as well as long-term trends of house, land and structure prices and quantities. I further show that if the elasticity of substitution between land and structures is 1, the model would generate very stable land share between 1950 and 2015, which is inconsistent with the data.

\section{Quantitative Results}

Two approaches have been adopted by previous studies to examine the house price cycle in the 2000s to understand relative contributions of different types of shocks. The first introduces a set of shocks in a calibrated model (Kiyotaki, Michaelides and Nikolov (2011); Favilukis, Ludvigson and Van Nieuwerburgh (2017); Kaplan, Mitman and Violante (2017)), and The second uses Bayesian estimation to determine the parameters and the shocks jointly (Iacoviello (2010); Liu, Wang and Zha (2013)).

I use a two-step approach. In the first step, I determine model parameters either directly from data or by ensuring a certain first-moment of the model that is sensitive to the parameter is the same as its data counterpart. In the second step, I consider four types of shocks between 2000 and 2015 - housing demand shocks, belief shocks, shocks to structure prices, and TFP shocks. I choose the size of these shocks such that four aggregate variables in my model (real output, real land price, real structure price, and the ratio of residential investment to the output of general consumption goods) are consistent with their data counterparts. ${ }^{2627}$

\section{A. Transmission Mechanisms}

In this subsection, I explore the transmission mechanisms for each type of shocks I introduce to explain the house price cycle in the 2000s: housing demand shocks, belief shocks, shocks to structure prices, and TFP shocks. I show the impulse

producing housing services is less than 1 , there is no steady-state balanced growth path unless the land quantity and the structure quantity grow at the same rate. This special condition, however, is not satisfied for the United States.

${ }^{26}$ I determine the persistence of the TFP shock based on the series constructed by Basu, Fernald and Kimball (2006); Fernald, Matoba et al. (2009); and Fernald (2014). As indicated earlier, TFP shocks are assumed to follow an $\mathrm{AR}(1)$ process, and the first-order autoregressive coefficient is estimated to be around 0.6. Since the impact of TFP shocks on house prices is limited, its shock persistence is not critical for my results.

${ }^{27}$ The following assumptions regarding the timing of the shocks help make the analysis of the housing cycle in the 2000s more tractable: (a) the model economy experiences a transition dynamics that starts in 1950, which is characterized in Appendix A5; (b) there are no shocks between 1950 and 2000 or after 2015 (except for a change far away in time from 2000-15 that makes the economy converge to the long-run steady state.); and (c) a set of shocks that have zero probability of occurrence ex ante hit the economy between 2000 and 2015. Appendix A5 explains the details in computing the equilibrium and the additional assumptions made to deal with the issue that returns may differ across assets ex post. The results should not be sensitive to these assumptions. 
responses of four housing variables to these shocks: user-cost-of-housing, the ratio of structure quantity to housing services quantity, house prices, and the ratio of house price to user-cost-of-housing.

Three patterns out of these exercises are particularly interesting and shed light on the housing cycle mechanism in this paper. First, user-cost-of-housing is sensitive to housing demand shocks but not belief shocks.

Second, smaller elasticity of substitution between land and structures in producing housing services amplifies the impact of housing demand shocks and belief shocks on house prices.

Third, smaller elasticity of substitution between land and structures in producing housing services dampens the response of residential investment to housing demand shocks and that of house prices to structure prices.

The first pattern suggests that if there is a strong rise in user-cost-of-housing, we should expect that housing demand shocks play an important role behind it. The second and third patterns highlight the critical role of elasticity of substitution between land and structures for a quantitative analysis of housing price and quantity.

I study the following shocks: the housing demand shock is an increase of 1 percentage point in housing preference of current and future generations. The belief shock is an increase of 1 percentage point in housing preference of future generations. The TFP shock is an increase in the total factor productivity of producing general consumption goods that leads to 1 percent increase in labor productivity. The shock to structure prices is an increase of 1 percent in residential structure price. All these shocks hit the economy in 2000.

Figure 2 shows smaller elasticity of substitution between land and structures strongly amplifies the responses of user-cost-of-housing and house price but significantly dampens the response of the ratio of structure quantity to housing services quantity to housing demand shocks.

[Figure 2 here]

Different from housing demand shocks, belief shocks have negligible impacts on user-cost-of-housing or the ratio of structure quantity to housing services quantity in the current period. The intuition is that the share of future generations in aggregate housing services consumption, which determines the responses of usercost-of-housing and the ratio of structure quantity to housing services quantity to belief shocks, is expected to rise slowly over time.

The impact of structure prices on house prices is significant, consistent with the fact that the share of structures in house value exceeded 60 percent around 2000. However, a smaller elasticity of substitution between land and structures significantly dampens the impact of structure prices on house prices. ${ }^{28}$

\footnotetext{
${ }^{28}$ Iacoviello and Neri (2010) does not consider low substitutability between land and structures. Lower substitutability dampens the impact of structure price increase on house prices by creating stronger downward pressure on land prices. Higher structure prices have two opposing effects on land prices: (1)
} 
TFP shocks have very limited impact on house prices compared with other types of shocks. Davis and Heathcote (2005) first points out that a model with TFP shocks cannot generate volatile house prices as observed in the data, which is confirmed by the finding here.

Figure 2 also reveals a sharp difference between housing demand shocks and belief shocks in terms of the response of the price-to-user-cost ratio-it is highly sensitive to belief shocks but not housing demand shocks.

The insensitivity of price-to-user-cost-ratio to housing demand shocks creates an issue for studies that find a dominant role of housing demand shocks in causing the house price boom in the 2000s (Iacoviello (2010) and Kaplan, Mitman and Violante (2017)): there was a large divergence between house price and the CPI rent. I will show that it is driven by the CPI rent not capturing user-cost-ofhousing well.

\section{B. The Housing Cycle in the 2000s}

In this subsection, I explore what are the main causes of the house price cycle in the 2000s. I show that user-cost-of-housing was much more volatile than the housing component of the CPI, and that housing demand played a key role in causing the house price boom.

\section{USER-COST-OF-HOUSING VERSUS THE CPI RENT}

Figure 3 shows the first main finding of this paper: a strong divergence between user-cost-of-housing and the CPI rent during the 2000s. The possibility of such a divergence is not considered by previous quantitative studies (Favilukis, Ludvigson and Van Nieuwerburgh (2017) and Kaplan, Mitman and Violante (2017)).

[Figure 3 here]

There are four remarks on this finding. First, due to the construction method, the CPI rent may contain significant measurement errors. The CPI rent is constructed using a rental-equivalence approach, which determines user-cost-ofhousing for an owner-occupied property through the following question: "if someone were to rent your home today, how much do you think it would rent for monthly, unfurnished and without utilities."

This rental-equivalence approach can be problematic: as highlighted by Gordon and Van Goethem (2004), an average renter is significantly different from an average homeowner. The average renter tends to be younger, less likely to be married, more likely to be financially constrained, and more exposed to moving shocks than the average homeowner. This difference strengthens the critique of Prescott (1997) that the rental-equivalence approach violates the principle that

reducing demand for land by weakening demand for housing services and (2) encouraging the substitution of residential structures by residential land. By weakening the second effect, smaller elasticity of substitution implies downward pressure on land prices. 
"the effective price of a commodity should be its cost to the household consuming it."

Second, the current approach relies on a plausible assumption. It is based on the assumption that investors do not wrongly attribute the expected capital gain of residences in good locations to the structures of homes. One piece of evidence is as follows. If investors cannot differentiate between the location and the structures of a home, one should expect the share of residential structures of new homes in residential investment to rise strongly during a housing boom, as new homes are much more structure intensive than old homes (Davis and Heathcote (2007)). This share, however, had been remarkably between 1980 and $2007 .{ }^{29}$

Third, there is micro evidence suggesting a divergence between the cost of owning and that of renting a home. For instance, Chinco and Mayer (2015) reports a divergence between user-cost-of-housing, which is called implied rent in their paper, and the market rent, in cities such as Las Vegas, Miami, and Phoenix.

Fourth, although user-cost-of-housing is not directly observed, the optimality condition implies that the consistency between its dynamics in the model and the data counterpart can be inferred from observables. I show that the model can match the ratio of structure quantity to housing service quantity and usercost-of-structures. Figure 3 shows that the model is broadly consistent with the ratio of structure quantity to house quantity and the ratio of house value to business value-added. ${ }^{30}$ As the ratio of house value to the output of nonhousing consumption goods depends on the expected return on housing and user-costof-structure depends on the structure price and the expected return on housing, these patterns provide some confidence that user-cost-of-housing in my model is consistent with its data counterpart. ${ }^{31}$

\section{DECOMPOSITION OF THE HOUSING CYCLE IN THE 2000S}

Figure 4 shows the second main finding of the paper: housing demand shocks rather than belief shocks were the main driver of the house price boom in the 2000s. It also shows that belief shocks play a critical role during the house price crash, explaining the entire deviation of the house price from its trend during the downturn. ${ }^{32}$

\footnotetext{
${ }^{29}$ Before 1980, there was a downward trend in it, and it crashed after 2007, followed by a mild rebound.

${ }^{30}$ The house quantity is defined as the house value deflated by the house price and has a different trend compared with the housing service quantity. However, in the short run, the difference between the ratio of structure quantity to house quantity and that of structure quantity to housing service quantity is small. I plot the the ratio of structure quantity to house quantity, because the housing service quantity is not directly observed in the data.

${ }^{31}$ Note that the model matches structure prices and their trend. Appendix $A 5$ describes how I define the structure price process. One can verify that the logarithm of real structure prices (defined as nominal structure prices deflated by CPI) can be quite accurately characterized by a linear trend plus a term that is defined as the logarithm of oil prices multiplied by a constant. As oil futures often give fairly flat time profiles for future oil prices, the structure price process characterized in this paper should provide a good first-order approximation. I do not expect the results to be sensitive to a deviation from this process, and leave this issue for future research.

${ }^{32}$ The contribution of a shock to the house price is computed through an exercise in which I shut off all the shocks but the one of interest. The contribution is then defined as the difference between
} 
Consistent with earlier findings on impulse responses, Panel a of Figure 4 suggests that belief shocks contributed very little to changes in user-cost-of-housing, whose strong rise was mainly caused by housing demand shocks and shocks to structure prices.

There are two interesting patterns in Figure 4. First, the deviation of house prices from their trend caused by belief shocks had been remarkably stable between 2002-07, which is at odds with characterizing the house price boom in this period as a rational bubble - a rational bubble should grow at a rate close to the real interest rate.

Second, should there be housing demand shocks or/and shocks to structure prices only, house prices would simply converge back to their trend after 2006, without going below it. Also, the co-movement between the contribution of housing demand shocks and that of shocks to structure prices makes it plausible that changes in structure prices were driven by housing demand shocks as well. For instance, Iacoviello and Neri (2010) shows a mechanism in which real structure prices are sensitive to housing demand shocks.

Figure 4 also reveals that a negative belief shock played a larger role than a negative housing demand shock in driving down house prices between 2007-08. Another strong deterioration in sentiment occurred between 2010-11.

\section{Robustness Tests and Discussion}

In this section, I show that the two main findings of this paper are robust to having a larger elasticity of substitution between land and structures in producing housing services, and to a different form of belief shocks. I also discuss the metric used to measure belief-driven house price cycles.

\section{A. Larger Elasticity of Substitution Between Land and Structures in Producing Housing Services}

To see how the two main findings are robust to a larger elasticity of substitution between land and structures, I let the housing services production function take a Cobb-Douglass form, and choose the land share in the Cobb-Douglass production function such that the land share in house value in 2000 is the same as its data counterpart.

Figure 6 shows that the elasticity of substitution between land and structures in producing housing services plays a quantitatively important role in both findings. The increase in user-cost-of-housing between 2000 and 2006 would be only $20 \%$ under the Cobb-Douglass production function, down from $30 \%$ in the case of smaller elasticity of substitution between land and structures.

house prices in the exercise and the underlying trend. I conduct a robustness test using an alternative definition, by keeping all shocks but the one of interest alive. The contribution is then defined as the difference between the house price when all shocks are present and the house price in the exercise. The results of the two exercises are almost the same, suggesting little interaction between different shocks. 
A larger disconnect between house price and user-cost-of-housing is consistent with a larger role of belief shocks in causing the house price boom. Its contribution to the deviation of the national house price from its trend in 2006 would be about $16 \%$ under the Cobb-Douglass production function, up from $5 \%$ in the previous case.

However, note that even with such a larger elasticity of substitution between land and structures, belief shocks explained only about half of the house price boom, measured by the deviation of house price from its trend. As the housing supply becomes more elastic under a Cobb-Douglass production function, the house price trend is growing more slowly, and the deviation of house prices from the trend in 2006 would be around $30 \%$.

This pattern suggests that a much less important role of belief shocks in causing the house price boom in this paper comes from not only a smaller elasticity of substitution between land and structures in producing housing services, but also an explicit consideration of housing demand shocks and shocks to structure prices. Both elements are not considered by Kaplan, Mitman and Violante (2017).

\section{B. Other Forms of Belief Shocks}

To illustrate the robustness of the two main findings to the form of belief shocks, I replace the shock to housing preference of future generations with shocks to long-term productivity growth rate ("growth shocks"). Kiyotaki, Michaelides and Nikolov (2011) finds growth shocks to be a powerful driver of house price cycles in a small open economy. ${ }^{33}$

Figure 6 shows that the findings of this paper are robust to the form of belief shocks: user-cost-of-housings was much more volatile than the CPI rent, and housing demand shocks explained most of the house price boom in the $2000 \mathrm{~s}$. The only significant discrepancy emerges for user-cost-of-housing between 2010 and 2011 , and the reason is that a strong decline in long-term growth rate mentioned above leads to substantial change in interest rates.

As house prices are not sensitive to growth shocks in a closed economy, a large permanent decline in the long-term productivity growth rate of 6 percentage points between 2010 and 2011 was needed to match the house price decline that year. ${ }^{34}$ This implausibly large decline in long-term growth rate suggests that the pessimism causing the crash in house prices between 2010 and 2011 should not be entirely attributed to the concern about future growth, and perhaps more about future demand for housing services in the form of preference shocks.

\footnotetext{
${ }^{33}$ Kahn (2009) explores a regime switching shock that affects productivity in his model in which there is limited substitutability between housing and nonhousing consumption, arguing that swings in productivity can justify the timing of and the sizable change in house prices in the 2000s.

${ }^{34}$ Another reason a growth shock of such a large magnitude is needed to explain the house price decline between 2010 and 2011 is that structure prices had already started to recover; what implies that the decrease in house prices was caused by a strong decline in land prices. To be consistent with this strong decline in land prices, the decline in the long-term growth rate needs to be large. The reason house prices are not sensitive to growth shocks is that endogenous changes of interest rate weaken the impact of growth shocks on house prices.
} 


\section{The Metric of Belief-Driven House Price Cycles}

This subsection explores what indicators can be potentially useful to capture belief-driven house price cycles. The findings of this paper challenge traditionally used metrics for assessing whether there is a housing bubble, such as whether there is a divergence between user-cost-of-housing and rent (Himmelberg, Mayer and Sinai (2005); Mayer (2011); Chinco and Mayer (2015)), and the ratio of price to rent. Both can be driven by demand for housing services.

Figure 7 shows that the ratio of house price to user-cost-of-housing rose only modestly during the boom, and the driver of this ratio is mainly belief shocks. So the conventional wisdom that a divergence between the house price and the cost of housing is an indication of a belief-driven house price cycle can still hold once we replace the rent with user-cost-of-housing.

\section{Concluding Remarks}

This paper studies what were the main causes of the house price cycle in the 2000s in the United States. I find that four fifths of the house price boom was caused by housing demand shocks and the remaining one fifth mainly by belief shocks. Belief shocks explain the entire deviation of the house price from its trend during the downturn.

To separate the roles of the two types of shocks, a key observation is that usercost-of-housing is sensitive to housing demand shocks but not to belief about future house prices, which implies that determining the change in user-cost-ofhousing can help the separation.

I overcome the challenge that user-cost-of-housing is not observed for owneroccupied properties and avoid making a direct assumption about expected future house prices, by utilizing the optimality condition of producing housing services that user-cost-of-housing is equal to the cost of structures divided by the marginal productivity of structures in producing housing services.

I show that user-cost-of-housing increased strongly during the housing boom in the 2000s, reflecting a combination of a residential investment boom, a limited supply of land, and a small elasticity of substitution between land and structures in producing housing services - they imply a strong decline in the marginal productivity of structures in producing housing services.

I find that the elasticity of substitution between land and structures is around 0.25 in the US economy at the national level, which amplifies the impact of housing demand shocks on house prices. Previous quantitative macroeconomic studies often assume that it is equal to 1.

To obtain this elasticity of substitution, I utilize again the optimality conditions of producing housing services, which implies that it can be estimated from a cointegration relationship between the log ratio of land value to structure value and the log ratio of land price to structure price, under the assumption that the price to user cost ratio is stationary. 
The findings of this paper challenge traditionally used metrics for assessing whether there is a housing bubble, such as whether there is a divergence between user-cost-of-housing and rent, and the ratio of price to rent. My findings suggest that strong changes in both measures can be caused by demand for housing services rather than a shift in belief about future house prices. I also find that by replacing rent with user-cost-of-housing in the ratio of price to rent, the ratio of price to user-cost-of-housing is a metric capturing belief shift that is disconnected with today's fundamentals.

There are two interesting issues that are not resolved in this paper: (i) what affects a cyclical divergence between user-cost-of-housing and the CPI rent? (ii) what is the micro-foundation of housing demand shocks?

\section{REFERENCES}

Akerlof, George A, and Robert J Shiller. 2010. Animal spirits: How human psychology drives the economy, and why it matters for global capitalism. Princeton university press.

Barberis, Nicholas, Robin Greenwood, Lawrence Jin, and Andrei Shleifer. 2018. "Extrapolation and bubbles." Journal of Financial Economics.

Basu, Susanto, John G Fernald, and Miles S Kimball. 2006. "Are technology improvements contractionary?" American Economic Review, 96(5): 14181448 .

Bernanke, Ben S, and Mark Gertler. 2001. "Should central banks respond to movements in asset prices?" American Economic Review, 91(2): 253-257.

Boskin, Michael J, Ellen L Dulberger, Robert J Gordon, Zvi Griliches, and Dale W Jorgenson. 1998. "Consumer prices, the consumer price index, and the cost of living." Journal of economic perspectives, 12(1): 3-26.

Burnside, Craig, Martin Eichenbaum, and Sergio Rebelo. 2016. "Understanding booms and busts in housing markets." Journal of Political Economy, 124(4): 1088-1147.

Capozza, Dennis R, and Robert W Helsley. 1989. "The fundamentals of land prices and urban growth." Journal of urban economics, 26(3): 295-306.

Cheng, Ing-Haw, Sahil Raina, and Wei Xiong. 2014. "Wall Street and the housing bubble." American Economic Review, 104(9): 2797-2829.

Chinco, Alex, and Christopher Mayer. 2015. "Misinformed speculators and mispricing in the housing market." The Review of Financial Studies, 29(2): 486522.

Davis, M., and J. Heathcote. 2005. "HOUSING AND THE BUSINESS CYCLE*." International Economic Review, 46(3): 751-784. 
Davis, Morris A, and Jonathan Heathcote. 2007. "The price and quantity of residential land in the United States." Journal of Monetary Economics, 54(8): 2595-2620.

Davis, Morris A, and Stijn Van Nieuwerburgh. 2015. "Housing, finance, and the macroeconomy." In Handbook of regional and urban economics. Vol. 5, 753-811. Elsevier.

Davis, Morris A, Jonas DM Fisher, and Toni M Whited. 2014. "Macroeconomic implications of agglomeration." Econometrica, 82(2): 731-764.

Díaz, Antonia, and María José Luengo-Prado. 2008. "On the user cost and homeownership." Review of Economic Dynamics, 11(3): 584-613.

Favilukis, Jack, Sydney C Ludvigson, and Stijn Van Nieuwerburgh. 2017. "The macroeconomic effects of housing wealth, housing finance, and limited risk sharing in general equilibrium." Journal of Political Economy, 125(1): 140-223.

Fernald, John. 2014. "A quarterly, utilization-adjusted series on total factor productivity." Federal Reserve Bank of San Francisco.

Fernald, John, Kyle Matoba, et al. 2009. "Growth accounting, potential output, and the current recession." FRBSF Economic Letter, 26.

Galí, Jordi. 2014. "Monetary policy and rational asset price bubbles." American Economic Review, 104(3): 721-52.

Garner, Thesia I, and Randal Verbrugge. 2009. "Reconciling user costs and rental equivalence: Evidence from the US consumer expenditure survey." Journal of Housing Economics, 18(3): 172-192.

Garriga, Carlos, Rodolfo Manuelli, and Adrian Peralta-Alva. 2012. "A model of price swings in the housing market."

Glaeser, Edward, and Joseph Gyourko. 2018. "The economic implications of housing supply." Journal of Economic Perspectives, 32(1): 3-30.

Glaeser, Edward L. 2013. "A nation of gamblers: Real estate speculation and American history." American Economic Review, 103(3): 1-42.

Glaeser, Edward L, and Charles G Nathanson. 2015. "Housing bubbles." In Handbook of regional and urban economics. Vol. 5, 701-751. Elsevier.

Glaeser, Edward L, and Joseph Gyourko. 2007. "Arbitrage in housing markets." National Bureau of Economic Research.

Glaeser, Edward L, Joseph Gyourko, and Raven E Saks. 2005. "Why have housing prices gone up?" American Economic Review, 95(2): 329-333. 
Gordon, Robert J, and Todd Van Goethem. 2004. "A Century of Downward Bias in the Most Important Component of the CPI: The Case of Rental Shelter, 1914-2003." Hard-to-Measure Goods and Services: Essays in Memory of Zvi Griliches, Studies in Income and Wealth, , (67).

Greenwood, Robin, Andrei Shleifer, and Yang You. 2018. "Bubbles for fama." Journal of Financial Economics.

Hanse, Gary D. 1993. "The cyclical and secular behaviour of the labour input: Comparing efficiency units and hours worked." Journal of Applied Econometrics, 8(1): 71-80.

Himmelberg, Charles, Christopher Mayer, and Todd Sinai. 2005. "Assessing high house prices: Bubbles, fundamentals and misperceptions." Journal of Economic Perspectives, 19(4): 67-92.

Hsieh, Chang-Tai, and Enrico Moretti. 2015. "Housing constraints and spatial misallocation." National Bureau of Economic Research.

Iacoviello, Matteo. 2010. "Housing in DSGE models: Findings and new directions." In Housing Markets in Europe. 3-16. Springer.

Iacoviello, Matteo, and Stefano Neri. 2010. "Housing market spillovers: evidence from an estimated DSGE model." American Economic Journal: Macroeconomics, 2(2): 125-64.

Justiniano, Alejandro, Giorgio E Primiceri, and Andrea Tambalotti. 2015. "Credit supply and the housing boom." National Bureau of Economic Research.

Kahn, James A. 2009. "Productivity Swings and Housing Prices." Current Issues in Economics and Finance, 15(3): 1.

Kaplan, Greg, Kurt Mitman, and Giovanni L Violante. 2017. "The housing boom and bust: Model meets evidence." National Bureau of Economic Research.

Kiyotaki, Nobuhiro, Alexander Michaelides, and Kalin Nikolov. 2011. "Winners and losers in housing markets." Journal of Money, Credit and Banking, 43(2-3): 255-296.

Kiyotaki, Nobuhiro, and John Moore. 1997. "Credit cycles." Journal of political economy, 105(2): 211-248.

Landvoigt, Tim, Monika Piazzesi, and Martin Schneider. 2015. "The housing market (s) of San Diego." American Economic Review, 105(4): 13711407. 
Lebow, David E, and Jeremy B Rudd. 2003. "Measurement error in the consumer price index: where do we stand?" Journal of economic literature, 41(1): 159-201.

Lian, Weicheng. 2019. "Structural Transformation in the United States Housing Markets." International Monetary Fund.

Liu, Zheng, Pengfei Wang, and Tao Zha. 2013. "Land-price dynamics and macroeconomic fluctuations." Econometrica, 81(3): 1147-1184.

Li, Wenli, and Rui Yao. 2007. "The life-cycle effects of house price changes." Journal of Money, Credit and banking, 39(6): 1375-1409.

Mankiw, N Gregory, and David N Weil. 1989. "The baby boom, the baby bust, and the housing market." Regional science and urban economics, 19(2): 235-258.

Mayer, Christopher. 2011. "Housing bubbles: A survey." Annu. Rev. Econ., 3(1): $559-577$.

Moulton, Brent R. 1996. "Bias in the consumer price index: what is the evidence?" Journal of Economic perspectives, 10(4): 159-177.

Nathanson, Charles G, and Eric Zwick. 2017. "Arrested development: Theory and evidence of supply-side speculation in the housing market." National Bureau of Economic Research.

Piazzesi, Monika, and Martin Schneider. 2016. "Housing and macroeconomics." In Handbook of Macroeconomics. Vol. 2, 1547-1640. Elsevier.

Prescott, Edward C. 1997. "On defining real consumption." Federal Reserve Bank of St. Louis Review, 79(3): 47.

Scheinkman, Jose A, and Wei Xiong. 2003. "Overconfidence and speculative bubbles." Journal of political Economy, 111(6): 1183-1220.

Shiller, Robert C. 2000. "Irrational exuberance." Philosophy \& Public Policy Quarterly, 20(1): 18-23.

Verbrugge, Randal. 2008. "The puzzling divergence of rents and user costs, 1980-2004." Review of Income and Wealth, 54(4): 671-699. 

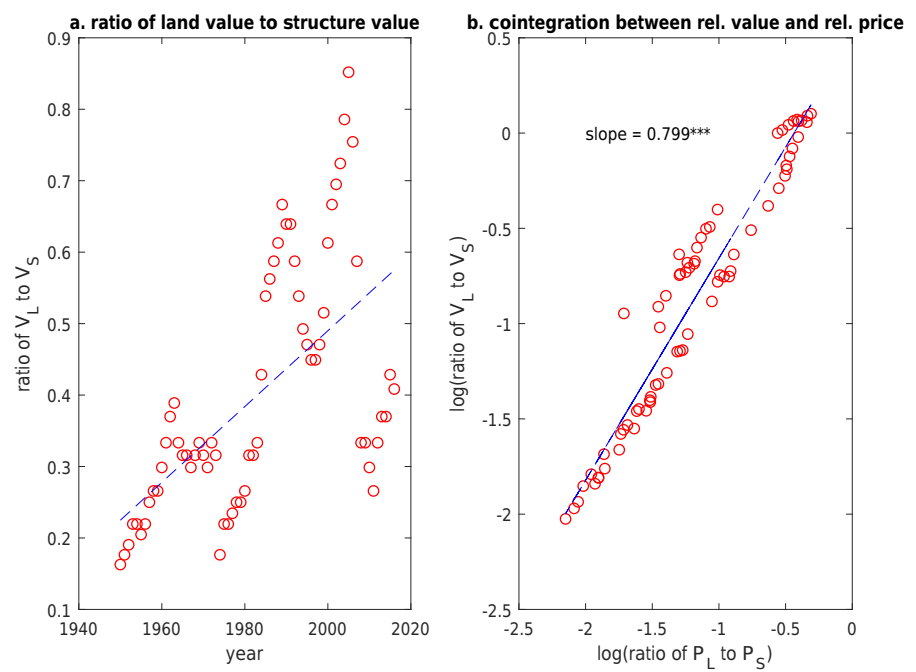

Figure 1. : Ratios of Value of Residential Land to Value of Residential Structures, 1950 - 2016, and Long-run Relationship Between this Ratio and the Ratio of Price of Land to Price of Structures

Sources: Flow of Funds, Davis and Heathcote (2007), and the author's calculations.

Note: $V_{L}$ : the aggregate value of residential land; $V_{S}$ : the aggregate value of residential structures; $P_{L}$ : the price of land; $P_{S}$ : the price of structures. Figure suggests that there is an upward trend for the ratio of the aggregate value of residential land to the aggregate value of residential structures, and a strong positive correlation between the ratio of the aggregate value of residential land to the aggregate value of residential structures and the ratio of the price of land to the price of structures. Panel a is based on data from the Flow of Funds for 1950-2016. The pattern would be similar if the indexes constructed by Davis and Heathcote (2007) were used instead. Panel b is based on the indexes of price and value of residential land and residential structures from Davis and Heathcote (2007) (which is further extended by Morris Davis to 2016Q1) and covers the 1930-2016 period. 
1. Housing demand shocks
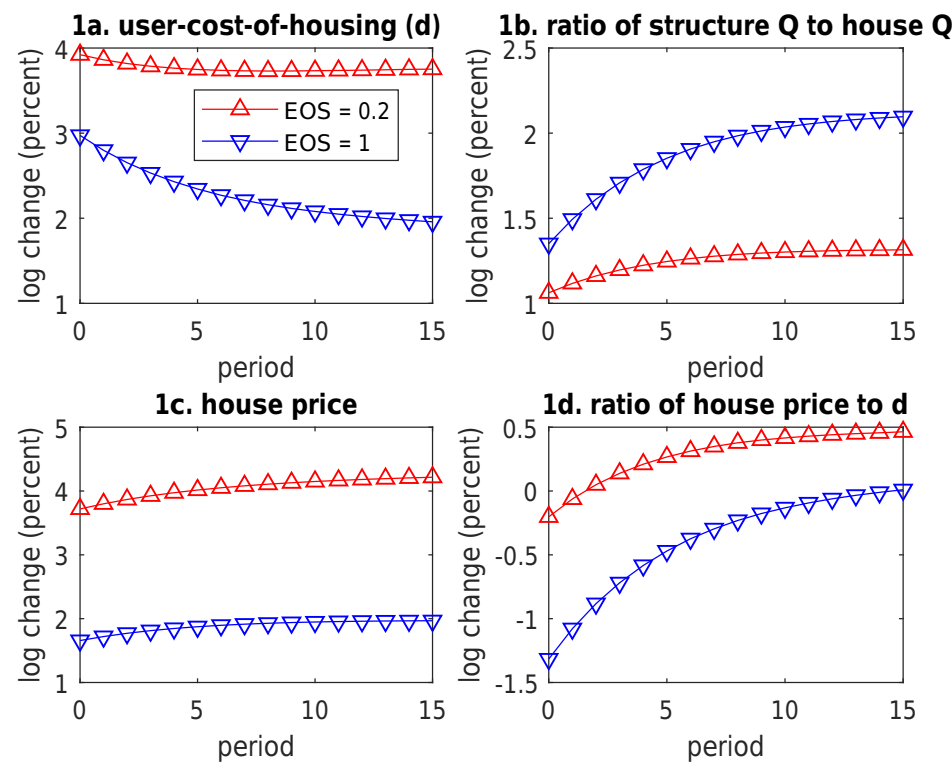

2. Belief shocks

2a. user-cost-of-housing (d)
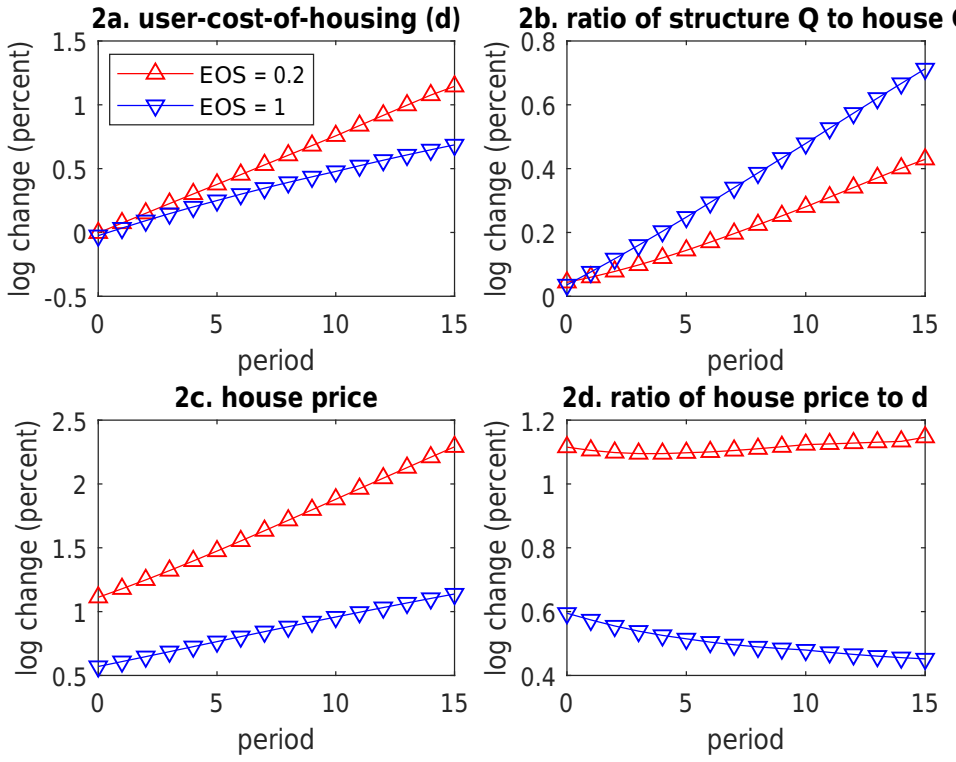

CInternational Monetary Fund. Not for Redistribution 
3. Shocks to structure prices
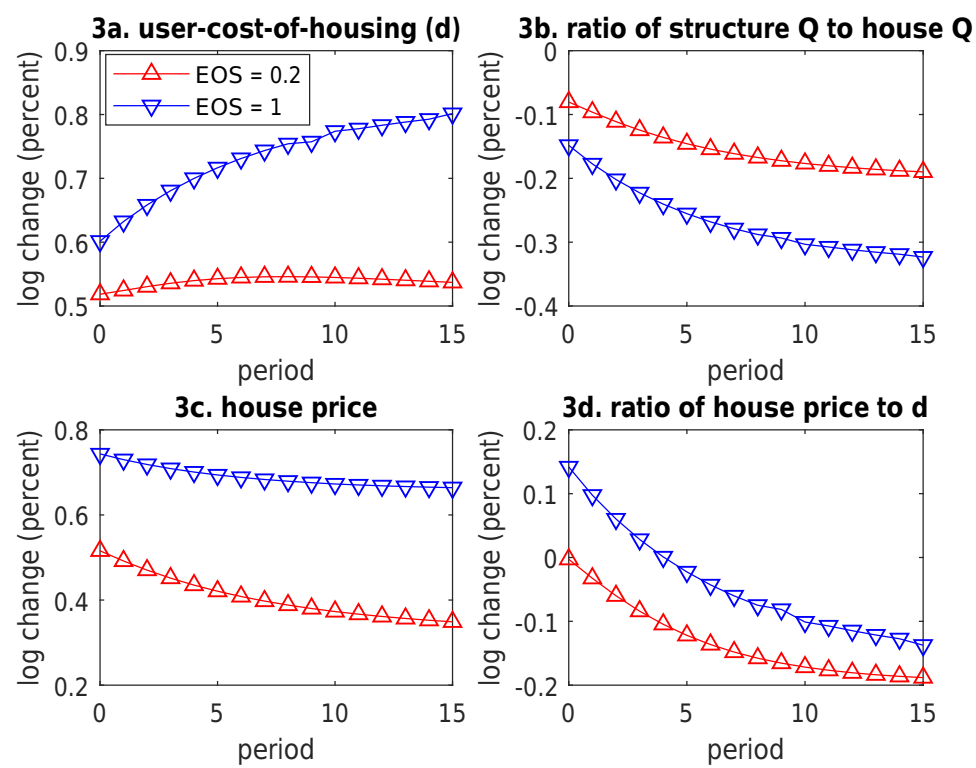

4. TFP shocks
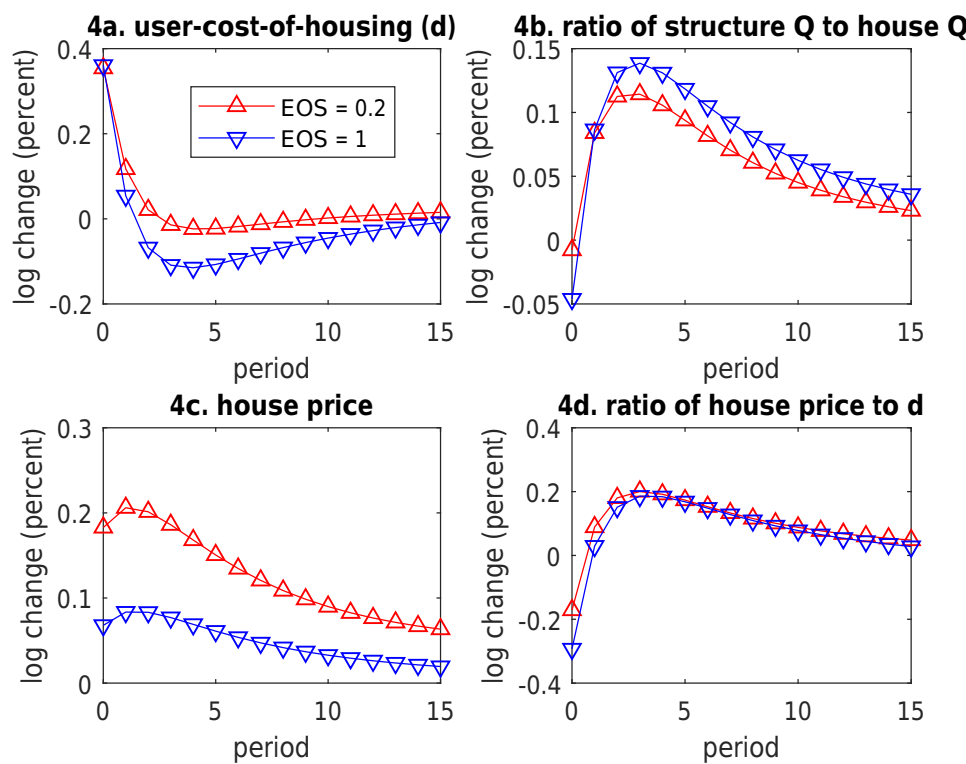

Figure 2. : Impulse Responses of Key Housing Variables to Shocks

Source: the author's calculations.

Note: Panel 1 shows the responses of housing variables to a 1 percentage point increase in the weight of housing services in the household utility function for both current and future generations. Panel 2 shows the responses to a 1 percentage point increase in the weight of housing services in utility function for future generations only. Panel 3 shows the responses to a 1 percent increase in the price of residential structures. Panel 4 shows the responses to a 1 percent increase in the level of productivity of nonhousing goods. The blue curve plots the case in which the elasticity of substitution between land and structures is 1 , and the red curve the case of 0.248 . 


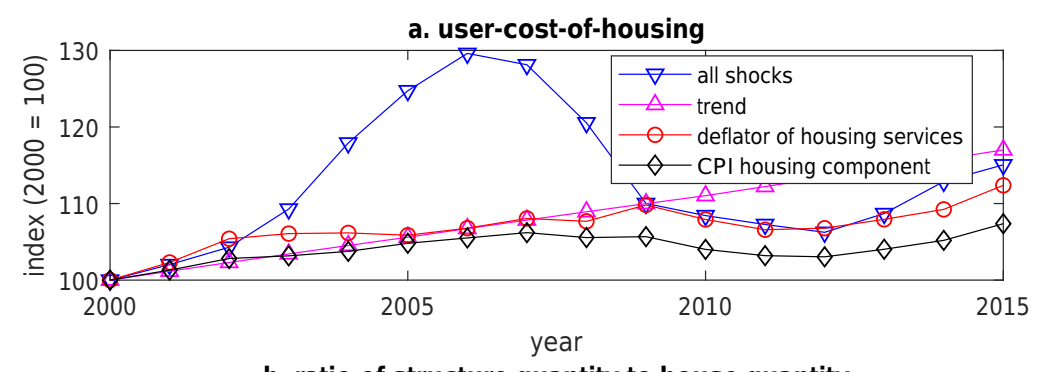

b. ratio of structure quantity to house quantity

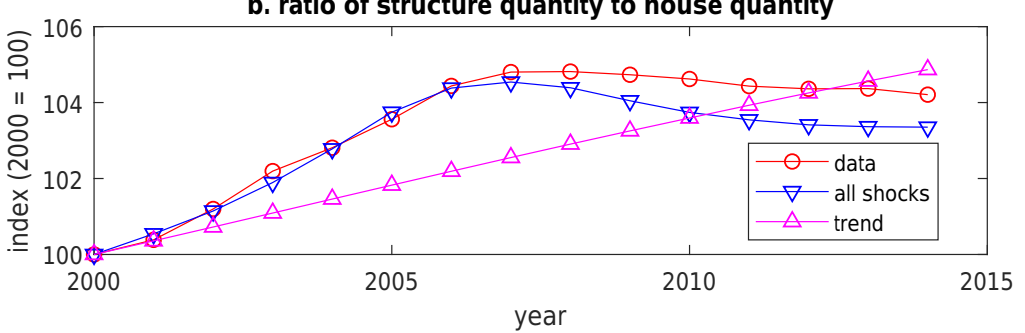

c. ratio of house value to the output of non-housing goods

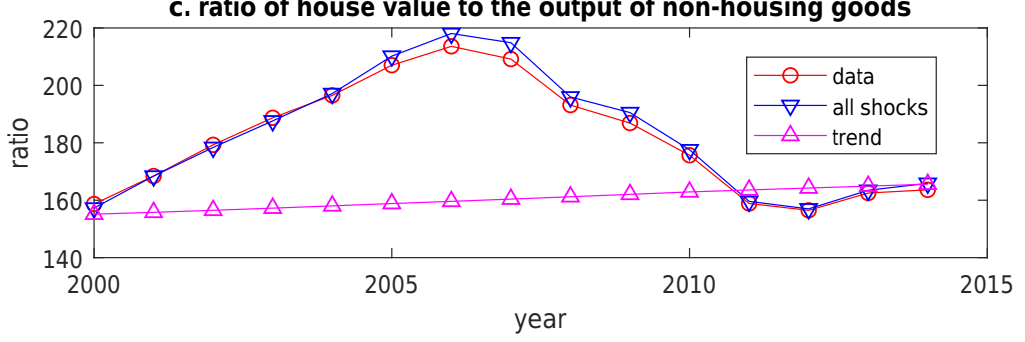

Figure 3. : User-cost-of-housing, Ratio of Quantity of Structure to Quantity of House, and Ratio of House Value to the Output of Nonhousing Goods, 2000-15

Sources: Bureau of Labor Statistics, National Income and Product Accounts, and the author's calcula-

Nions: Figure suggests that the model matches user-cost-of-housing based on the first-order condition that user-cost-of-housing is equal to user-cost-of-structures divided by the marginal productivity of structures in producing housing services. As the quantity of house stock rather than the quantity of housing service is observed in the data, panel b plots the ratio of the quantity of residential structures to the quantity of house stock to suggest that it matches the ratio of the quantity of residential structures to the quantity of housing services well. Similarly, the return to housing is not directly observed in the data, and panel c shows that the model matches the ratio of house value to business value-added, which depends on the return to housing, well. 

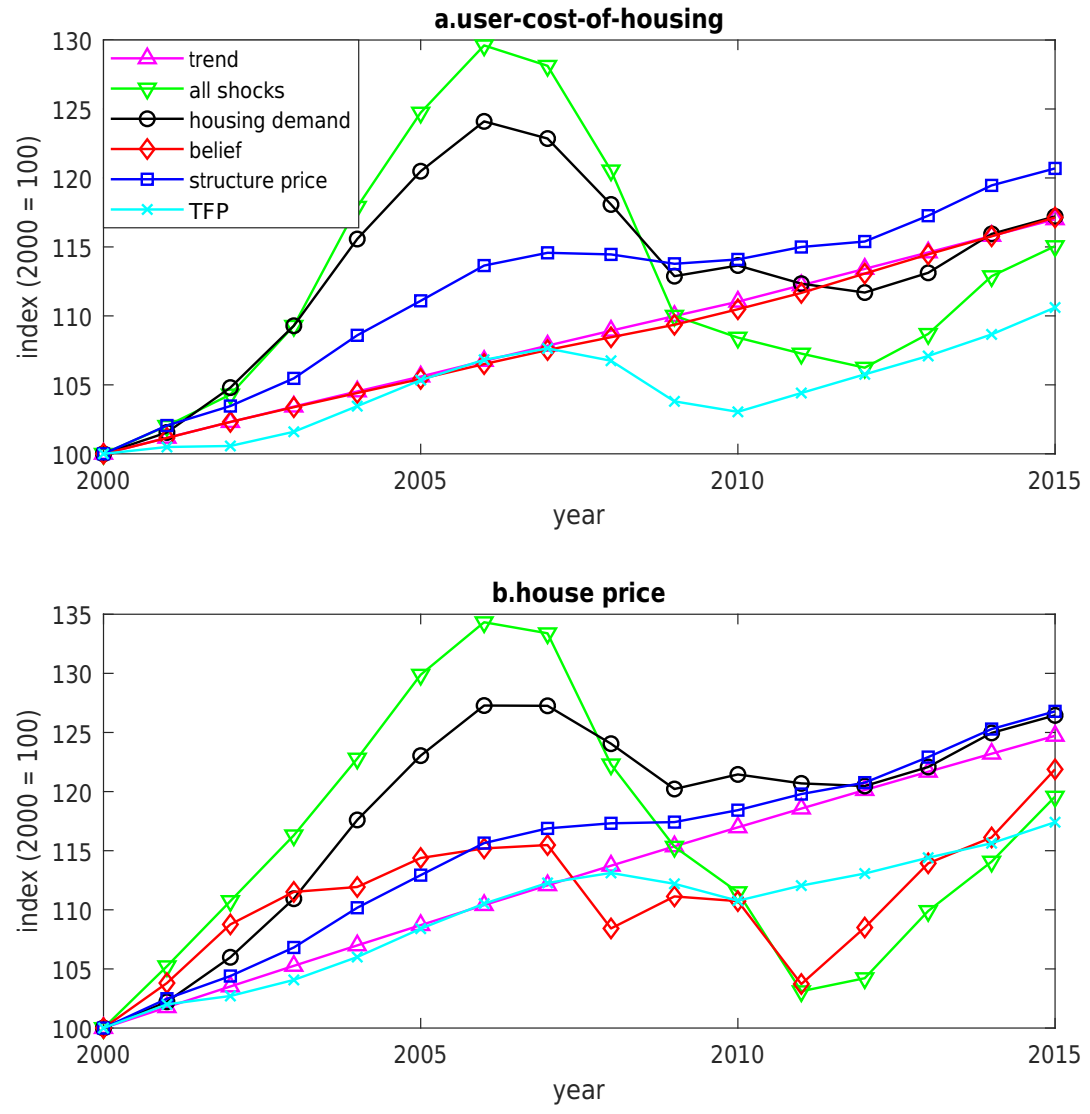

Figure 4. : User-cost-of-housing and House Price, 2000-15

Source: the author's calculations.

Note: Trend refers to the case with no shocks. Figure shows that the strong increases in both user-costof-housing and house price are both mainly driven by housing demand shocks. Belief shocks, however, explain the entire deviation of the house price from its trend during the downturn. 

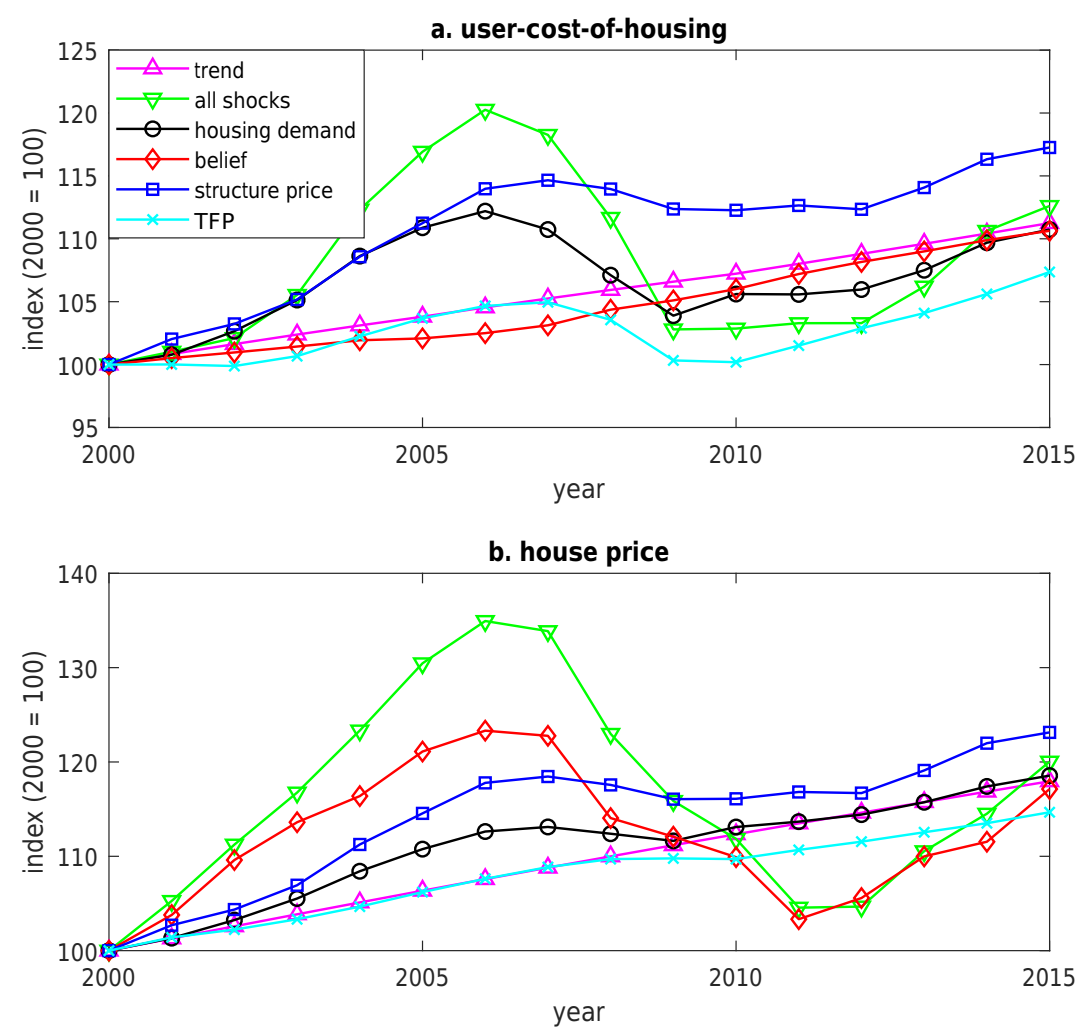

Figure 5. : User-cost-of-housing and House Price under a Cobb-Douglass Aggregate Housing Service Production Function, 2000-15

Source: the author's calculations.

Note: Figure plots user-cost-of-housing and house price under different configurations of shocks when the aggregate housing services production function takes a Cobb-Douglass form. The share of land in the production technology is chosen such that the share of land in aggregate house value in 2000 is equal to its data counterpart. 

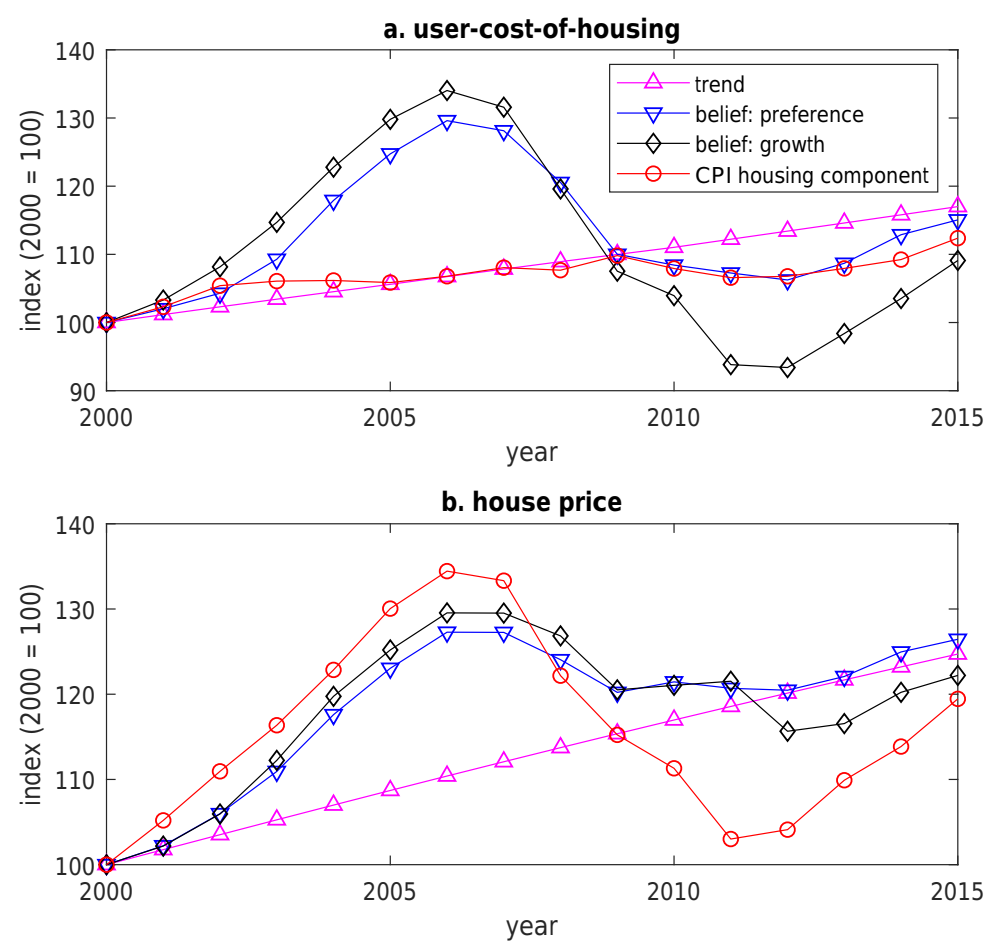

Figure 6. : User-cost-of-housing and House Price under Different Forms of Belief Shocks, 2000-15

Source: Bureau of Labor Statistics, Davis and Heathcote (2007), and the author's calculations.

Note: Trend refers to the case with no shocks. Panel a plots the user-cost-of-housing under different configurations of shocks and the CPI housing component, and panel $\mathrm{b}$ the house price under different shocks and the data counterpart. "Belief: preference" refers to the case in which the belief shock is in the form of shocks to the housing preference of future generations. "Belief: growth" refers to the case in which belief shock is in the form of shocks to long-term productivity growth rate. 

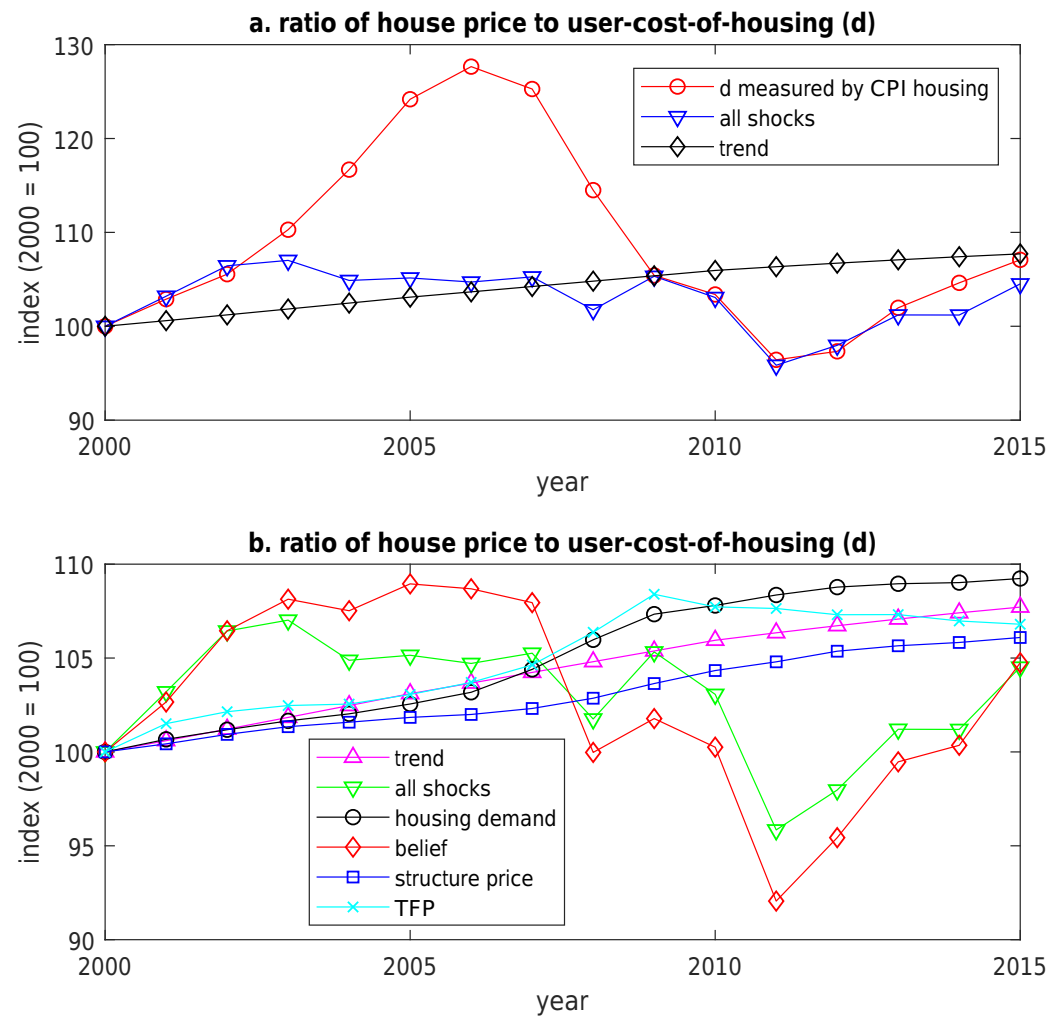

Figure 7. : Ratio of House Price to User-cost-of-housing, 2000-15

Sources: Bureau of Labor Statistics, and the author's calculations.

Note: Trend refers to the case with no shocks. Figure shows that the strong increases in both user-costof-housing and house price are both mainly driven by housing demand shocks. Belief shocks, however, explain the entire deviation of the house price from its trend during the downturn. 
Table 1-: The Model Parameters

\begin{tabular}{|c|c|c|}
\hline \multicolumn{3}{|c|}{ Housing and Nonhousing Goods Production Technology } \\
\hline Parameters & Value & Source \\
\hline $\begin{array}{l}\text { Elasticity of substitution between } \\
\text { land and structures in producing } \\
\text { housing services }(\rho)\end{array}$ & 0.248 & $\begin{array}{l}\text { Estimated from the prices and } \\
\text { quantities of developed land } \\
\text { and residential structures }\end{array}$ \\
\hline $\begin{array}{l}\text { Share of structures in the housing } \\
\text { services production function }(\phi)\end{array}$ & 0.973 & Determined inside the model \\
\hline Short-term elasticity of land supply $(\omega)$ & 0.497 & $\begin{array}{l}\text { Estimated from the land de- } \\
\text { velopment cost breakdown } \\
\text { provided by the National } \\
\text { Association of Home Builders }\end{array}$ \\
\hline Long-term elasticity of land supply $(\gamma)$ & 1.74 & $\begin{array}{l}\text { Estimated from the prices and } \\
\text { quantities of developed land }\end{array}$ \\
\hline $\begin{array}{l}\text { Share of capital in the production } \\
\text { function of nonhousing goods }(\alpha)\end{array}$ & 0.233 & Determined inside the model \\
\hline \multicolumn{3}{|c|}{ Household Preferences } \\
\hline Parameters & Value & Source \\
\hline $\begin{array}{l}\text { Elasticity of intertemporal substi- } \\
\text { tution }\end{array}$ & 1 & Standard in the literature \\
\hline Household discount rate $(\beta)$ & 0.943 & Determined inside the model \\
\hline $\begin{array}{l}\text { Share of housing services in house- } \\
\text { hold preference function }(1-\phi)\end{array}$ & 0.144 & $\begin{array}{l}\text { Estimated from the National } \\
\text { Income and Product Account }\end{array}$ \\
\hline \multicolumn{3}{|c|}{ Other Parameters } \\
\hline Parameters & Value & Source \\
\hline Depreciation rate of residential structures $\left(\delta^{S}\right)$ & 0.03 & $\begin{array}{l}\text { Estimated from the residen- } \\
\text { tial fixed asset table }\end{array}$ \\
\hline Depreciation rate of capital $\left(\delta^{K}\right)$ & 0.071 & $\begin{array}{l}\text { Estimated from the non- } \\
\text { residential fixed asset table }\end{array}$ \\
\hline
\end{tabular}

Source: the author's calculations.

Note: The share of structures in the housing services production function $(\phi)$, the share of capital in the production function of nonhousing goods $(\alpha)$, and the household discount rate $(\beta)$ are determined by ensuring the consistency between the following three variables in the model and their data counterparts: (1) the ratio of nonresidential investment to the output of nonhousing goods, (2) the ratio of residential investment to the output of nonhousing goods, and (3) the share of land in the aggregate housing value between 1950 and 2015 .

\section{CInternational Monetary Fund. Not for Redistribution}




\section{Online Appendix Not For Publichtion}

\section{A1. Definition of Variables and Data Sources}

The main data sources of the series used in this paper are:

(1) the quality-adjusted land and structure price and quantity indexes created by Davis and Heathcote (2007), which are extended by Morris Davis to 2016Q1 and available on his website (http://morris.marginalq.com;

http://datatoolkits.lincolninst.edu/subcenters/land-values/price-and-quantity.asp);

(2) the TFP series constructed by John Fernald and his co-authors

(https://www.frbsf.org/economic-research/indicators-data/

total-factor-productivity-tfp/);

(3) the labor efficient units over the life cycle provided by Hanse (1993);

(4) the detailed residential fixed asset table compiled by the Bureau of Economic

Analysis (BEA);

(5) the cost breakdown of land development and construction provided by the National Association of Home Builders (NAHB);

(6) the CPI housing component created by the Bureau of Labor Statistics;

(7) the national income and product accounts (NIPA) complied by BEA;

(8) the population data from the United States census bureau;

(9) the life tables from the centers of disease control and prevention (CDC);

(10) the World Population Prospects (I use the 2015 revision).

Table A1 lists the variables and their corresponding data sources.

\section{A2. Construction of Developed Land Price Index}

This subsection explains the construction of the quality-adjusted developed land price index. The key difference between this index and the quality-adjusted land price index created by Davis and Heathcote (2007) (DH) is that land development is part of residential land to construct my index and part of residential structures for $\mathrm{DH}$ to construct their index. I make this assumption as my model treats land development as part of residential land rather than residential structures. One debatable issue is what fraction of land development should be treated as non-depreciable over time, and Figure A1 suggests that the assumption about this fraction is not essential, as the developed land price index I construct, which is based on the assumption that all of land development does not depreciate over time, traces the raw land price index $\mathrm{DH}$ construct, which is based on the assumption that land development depreciates at the same rate as residential structures, very well.

I construct the quality-adjusted land price index $\left\{p_{t}^{L}\right\}_{t}$ using the same approach as DH construct their raw land index, and back out the land price inflation as the difference between the house price inflation and the residential structure price inflation, taking into account the weights of the land price and structure price inflation in the house price inflation (Equation (A1)). The difference relative to 


\section{Table A1-: Variables and Data Sources}

\begin{tabular}{|c|c|}
\hline $\begin{array}{l}\text { Constant-quality housing, } \\
\text { land and structure price and } \\
\text { value indexes }\end{array}$ & $\begin{array}{l}\text { The Lincoln Institute of Land Policy; constructed by Davis and } \\
\text { Heathcote (2007), and extended by Morris Davis to 2016Q1. }\end{array}$ \\
\hline $\begin{array}{l}\text { Total factor productivity; real } \\
\text { business sector output }\end{array}$ & $\begin{array}{l}\text { San Francisco Fed; constructed by Fernald (2014), Fernald and } \\
\text { Matoba (2009), and Basu, Fernald, and Kimball (2006). }\end{array}$ \\
\hline $\begin{array}{l}\text { Efficient labor units by } 5 \text {-year age } \\
\text { groups }(20-95)\end{array}$ & $\begin{array}{l}(0.7500,1.0150,1.06750,1.12000,1.12375,1.1275,1.10375 \text {, } \\
1.0800,0.9275,0,0,0,0,0,0,0) \text {, from Hanse }(1993) \text {. These } \\
\text { values are further linearly interplated to get the numbers for } \\
\text { 1-year age groups }\end{array}$ \\
\hline $\begin{array}{l}\text { Residential investment, gross } \\
\text { value added of business sectors, } \\
\text { personal consumption expenditure } \\
\text { by function, the price of housing sec- } \\
\text { tor output }\end{array}$ & $\begin{array}{l}\text { The Bureau of Economic Analysis; Table 1.1.5, 1.3.4, 1.3.5, } \\
\text { 2.5.4, 2.5.5, 7.4.4. }\end{array}$ \\
\hline $\begin{array}{l}\text { Cost breakdown of land development } \\
\text { and construction }\end{array}$ & the National Association of Home Builders (NAHB) \\
\hline $\begin{array}{l}\text { Detailed estimates for private } \\
\text { residential fixed assets }\end{array}$ & The Bureau of Economic Analysis. \\
\hline $\begin{array}{l}\text { The deflator of structures excluding } \\
\text { land development }\end{array}$ & $\begin{array}{l}\text { From detailed estimates for private residential } \\
\text { fixed assets. The deflator of "owner occupied, 1-4 units, addi- } \\
\text { tions and alterations". }\end{array}$ \\
\hline $\begin{array}{l}\text { The deflator of personal consumption } \\
\text { expenditure excluding housing }\end{array}$ & $\begin{array}{l}\text { From personal consumption expenditure by function. Defined } \\
\text { as a Laspeyres index of consumption items which include all } \\
\text { categories of personal consumption except for "rental of tenant- } \\
\text { occupied nonfarm housing", "imputed rental of owner-occupied } \\
\text { nonfarm housing", or "rental value of farm dwellings". }\end{array}$ \\
\hline $\begin{array}{l}\text { The residential investment in new } \\
\text { properties owned by households }\end{array}$ & $\begin{array}{l}\text { From detailed estimates for private residential fixed asssets. } \\
\text { The sum of investment in the following categories: "Owner- } \\
\text { occupied, 1-4 units, new", "Owner-occupied, } 5+\text { units, new", } \\
\text { "Tenant-occupied, 1-4 units, new", and "Tenant-occupied, } 5+ \\
\text { units, new". }\end{array}$ \\
\hline $\begin{array}{l}\text { Mortality rates, population size by } \\
\text { age group }\end{array}$ & $\begin{array}{l}\text { the United States census bureau, CDC, and the } 2015 \text { revision } \\
\text { of } \\
\text { the World Population Prospects }\end{array}$ \\
\hline
\end{tabular}

\section{CInternational Monetary Fund. Not for Redistribution}


$\mathrm{DH}$ is that I define the weight of land price inflation in house price inflation $\frac{V_{t-1}^{L}}{V_{t-1}^{H}}$ by assuming that land development is part of land rather than part of structures. For this purpose, I need to construct $V_{t-1}^{L}$ by including the land development.

The details go as follows: first of all, the equation (A1) is the key formula I operate to construct the developed land price index:

$$
\frac{p_{t}^{L}}{p_{t-1}^{L}}=\frac{\frac{p_{t}^{H}}{p_{t-1}^{H}}-\left(1-\frac{V_{t-1}^{L}}{V_{t-1}^{H}}\right) \frac{p_{t}^{S}}{p_{t-1}^{S}}}{\frac{V_{t-1}^{L}}{V_{t-1}^{H}}}
$$

where $\left\{p_{t}^{H}\right\}$ is the quality-adjusted housing price indexes developed by Davis and Heathcote (2007) (DH). Due to data constraints, they use different approaches to construct two series for the period of 1975Q1 - 2016Q1 and 1930 - 2000 separately. I splice the series in 1980, as DH constructs the series in the period of $1930-2000$ by ensuring its consistency with housing values in the census years. The results are, however, not sensitive to choosing a different splicing year. $p_{t}^{S}$ is the deflator of structures excluding land development, which is proxied by the deflator of "owner occupied, 1-4 units, additions and alterations", which comes from the detailed estimates for private residential fixed assets compiled by the Bureau of Economic Analysis (BEA). I choose this deflator as the proxy, because additions and alterations do not include land development. The deflators of different types of structures have very similar dynamics. $\frac{V_{t-1}^{L}}{V_{t-1}^{H}}$ is the share of developed land in house value in period $t-1$, and is constructed in three steps:

Step 1 let $\frac{V_{1930}^{L}}{V_{1930}^{H}}$, the share of developed land in house value in 1930 , be $\chi \frac{V_{1930}^{L, \text { raw }}}{V_{1930}^{H}}$, which is the share of raw land in house value in 1930 multiplied by a constant $\chi$. Here, $V_{1930}^{L, \text { raw }}$ is the aggregate value of raw land and $V_{1930}^{H}$ the aggregate value of house in 1930. For both series, I use the corresponding indexes constructed by DH. $\chi$ will be solved from a fixed point problem.

Step 2 For $t=1931, \ldots, 2015$, aggregate developed land value $V_{t}^{L}$ is calculated using a perpetual inventory method as follows:

$$
V_{t}^{L}=V_{t-1}^{L} \frac{p_{t}^{L}}{p_{t-1}^{L}}+V_{t}^{\mathrm{New}, \text { raw land }}+V_{t}^{\mathrm{New}, \text { land development }}
$$

in which $V_{t-1}^{L}$ is obtained in the previous step of iteration, $\frac{p_{t}^{L}}{p_{t-1}^{L}}$ can be computed based on equation (A1). I assume that $V_{t}^{\mathrm{New} \text {, land development }}=\omega_{t}\left(V_{t}^{\mathrm{New} \text {,raw land }}+\right.$ $V_{t}^{\text {New,land development }}$, which is consistent with the first-order condition of land developers. To be consistent with the calibration of the model, I choose $\omega_{t}=$ 0.497 , which is determined based on the land development cost breakdown in 2004 that is compiled by the National Association of Home Builders (NAHB) (Table A2). Here, an implicit assumption is that the share of land development 
in the aggregate value of newly developed residential land is stable over time. There are two pieces of evidences supporting this assumption. First, the share of finished lot cost in total cost of single-family units is broadly stable for single family homes (Table A3). Second, the share of raw land in total cost of singlefamily units is assumed to be stable by the Bureau of Economic Analysis in its construction of residential investment from new homes in the National Income and Product Accounts - the share is assumed to be $10.6 \%$.

The value of finished land $V_{t}^{\text {New,raw land }}+V_{t}^{\text {New, land development }}$ can hence be determined if we know the value of residential structures of new homes, denoted

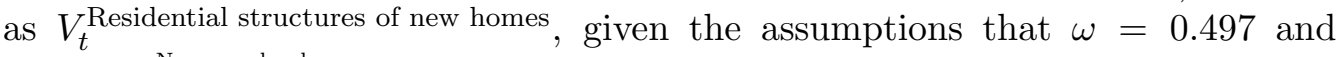

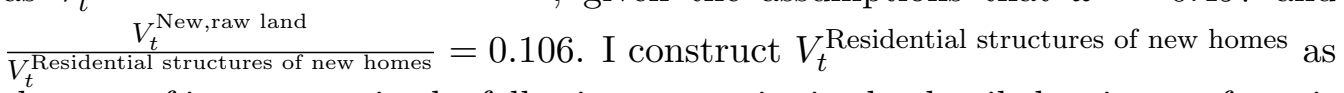
the sum of investment in the following categories in the detailed estimates for private residential fixed assets: "owner-occupied, 1-4 units, new", "owner-occupied, $5+$ units, new", "tenant-occupied, 1-4 units, new", and "tenant-occupied, 5+ units, new".

Step 3 For a given value of $\chi$, step 1 and 2 yield $\frac{V_{t}^{L}}{V^{\mathbf{L}} \text {, raw }}$ as a function of $\chi$, denoted as $\mu(\chi, t)$. Then, I solve $\chi$ from this equation:

$$
\chi=\frac{1}{2015-1930+1} \sum_{t=1930}^{2015} \mu(\chi, t)
$$

This yields $\chi=1.137$. Therefore, aggregate developed land value is $13.7 \%$ higher than aggregate raw land value. 


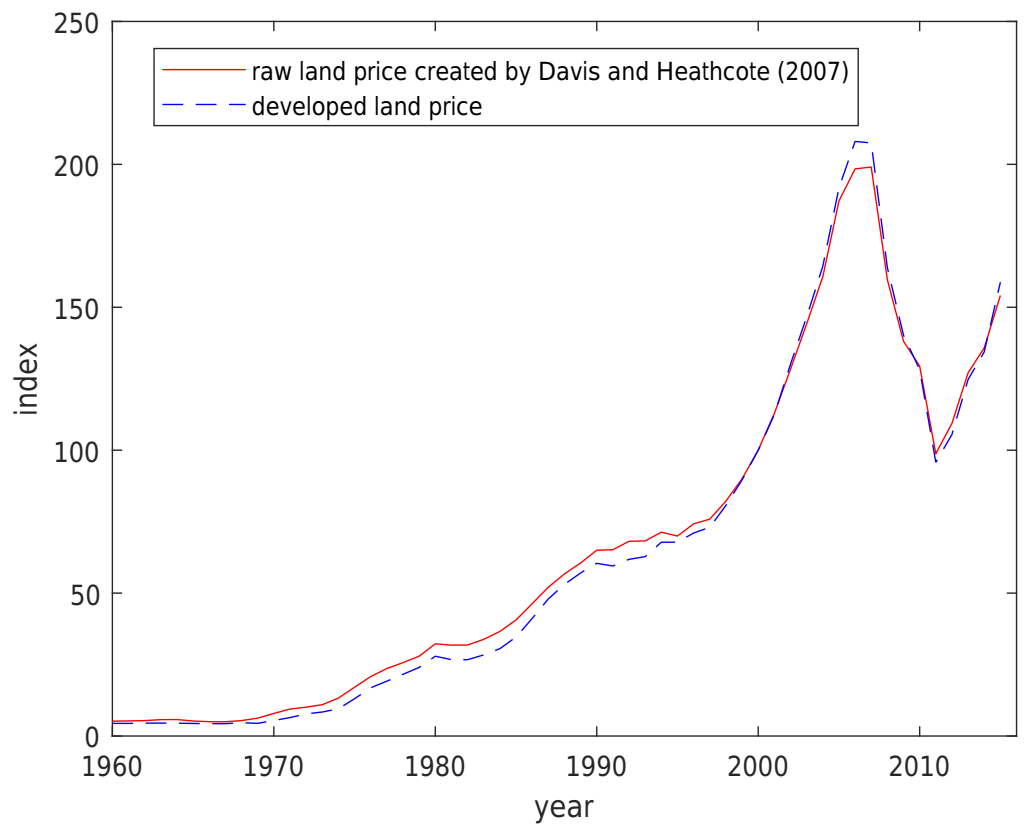

Figure A1. : User-cost-of-housing and House Price under Different Forms of Belief Shocks, 2000-15

Sources: Davis and Heathcote (2007), the detailed residential fixed asset table, the National Association of Home Builders (NAHB), and the author's calculations.

Note: Figure shows that the developed land price index traces the raw land price index very well when I normalize both to be 100 in 2000 . 
Table A2-: Finished Lot Cost Breakdown for Single-family Units in the United States in 2004

\begin{tabular}{lc}
\hline & \% of Lot Cost \\
\hline Raw Lot Cost & 0.503 \\
Development Costs: & \\
a. cost of processing approvals & 0.059 \\
b. site preparation & 0.071 \\
c. site improvement & 0.166 \\
-paving & 0.039 \\
-water and sewer & 0.052 \\
-erosion and sediment & 0.008 \\
d. impact analysis & 0.005 \\
e. water/electric hook-up & 0.018 \\
f. land dedication or fee in lieu & 0.001 \\
g. bonding/escrow fee & 0.005 \\
h. financing cost & 0.032 \\
i. tree preservation and planting & 0.017 \\
j. wetland preservation and planting & 0.023 \\
-value of unbuilt land & 0.019 \\
-cost of mitigation & 0.002 \\
k. value of land left unbuilt as green space or park & 0.004 \\
l. other costs & 0.095 \\
\hline
\end{tabular}

Sources: the National Association of Home Builders, 2004.

Table A3-: The Construction Cost Breakdown of Single Family Homes in the United States (1969-2011)

\begin{tabular}{lccccccccc}
\hline \hline & $\mathbf{1 9 6 9}$ & $\mathbf{1 9 8 2}$ & $\mathbf{1 9 9 5}$ & $\mathbf{1 9 9 8}$ & $\mathbf{2 0 0 2}$ & $\mathbf{2 0 0 4}$ & $\mathbf{2 0 0 7}$ & $\mathbf{2 0 0 9}$ & $\mathbf{2 0 1 1}$ \\
\hline 1. Finished Lot Cost & 0.21 & 0.24 & 0.24 & 0.24 & 0.24 & 0.26 & 0.25 & 0.20 & 0.22 \\
2. Total Construction Cost & 0.55 & 0.45 & 0.53 & 0.55 & 0.51 & 0.52 & 0.48 & 0.59 & 0.59 \\
3. Financing Cost & 0.07 & 0.15 & 0.02 & 0.02 & 0.02 & 0.02 & 0.02 & 0.02 & 0.02 \\
Other costs & 0.17 & 0.16 & & & & & & & \\
- 4. Overhead and General Expenses & & & 0.06 & 0.06 & 0.06 & 0.06 & 0.07 & 0.05 & 0.05 \\
- 5. Marketing Cost & & & 0.02 & 0.01 & 0.02 & 0.02 & 0.03 & 0.01 & 0.02 \\
- 6. Sales Commission & & & 0.03 & 0.03 & 0.04 & 0.03 & 0.04 & 0.03 & 0.03 \\
- 7. Profit & & & 0.09 & 0.09 & 0.12 & 0.10 & 0.11 & 0.09 & 0.07 \\
Total & 1.00 & 1.00 & 1.00 & 1.00 & 1.00 & 1.00 & 1.00 & 1.00 & 1.00 \\
\hline
\end{tabular}

Source: NAHB Constructioin Cost Surveys, 1969 - 2011. 


\section{A3. Definition of Perfect Foresight Equilibrium}

A perfect foresight equilibrium in period $t$ given $K_{t}, L_{t-1}, S_{t-1},\left\{Z_{t+s}, P_{t+s}^{S}, \phi_{t+s}^{t+s-a}\right.$, $\left.n_{t+s}^{t+s-a}\right\}_{s=0, \ldots, \infty ; a=0, \ldots, T-1}$, is defined as the prices $\left\{R_{t+s}, P_{t+s}^{L}, P_{t+s}^{S}, d_{t+s}, w_{t+s}, r_{t+s}\right\}_{s=0, \ldots, \infty}$ and the allocations: $\left\{K_{t+s}, N_{t+s}, L_{t+s}, S_{t+s}, H_{t+s}, Y_{t+s}^{L}, c_{t+s+a}^{t+s}, h_{t+s+a}^{t+s}, b_{t+s+a}^{t+s}\right\}_{s=0, \ldots, \infty, a=0, \ldots, T-1}$, such that

(a) $K_{t+s}$ and $N_{t+s}$ solve the problem (1);

(b) $Y_{t+s}^{L}$ solves the problem (2), given $P_{t+s}^{L}$ and $L_{t+s-1}$;

(c) $\left\{L_{t+s}\right\}_{s=0, \ldots, \infty}$ and $\left\{S_{t+s}\right\}_{s=0, \ldots, \infty}$ solve the problem (5), given $\left\{R_{t+s}, P_{t+s}^{L}, P_{t+s}^{S}\right\}_{s=0, \ldots, \infty}$.

(d) $\left\{c_{t+s+a}^{t+s}, h_{t+s+a}^{t+s}, b_{t+s+a}^{t+s}\right\}_{a=0, \ldots, T-1}$ solve the problem (6), given $\left\{R_{t+s+a-1}, w_{t+s+a}, d_{t+s+a}\right.$, $\left.T_{t+s+a}\right\}_{s=0, \ldots, \infty ; a=0, \ldots, T-1}$.

The following markets clear:

(i) Nonhousing goods: $\sum_{a=0}^{T-1} n_{t+s}^{t+s-a} c_{t+s}^{t+s-a}+Y_{t+s}^{L}+P_{t+s}^{S}\left[S_{t+s}-\left(1-\delta^{S}\right) S_{t+s-1}\right]$ $+\left[K_{t+s+1}-\left(1-\delta^{K}\right) K_{t+s}\right]=K_{t+s}^{\alpha}\left(Z_{t+s} N_{t+s}\right)^{1-\alpha}$

(ii) Housing services: $\sum_{a=0}^{T-1} n_{t+s}^{t+s-a} h_{t+s}^{t+s-a}=H\left(S_{t+s}, L_{t+s}\right)$;

(iii) Developed land: $L_{t+s}-L_{t+s-1}=A^{L} L_{t+s-1}^{-\gamma}\left(Y_{t+s}^{L}\right)^{\omega}$.

(iv) Labor: $N_{t+s}=\sum_{a=0}^{T-1} n_{t+s}^{t+s-a} l^{a}$;

(v) Funds: $K_{t+s+1}+\frac{V_{t+s+1}^{L}+V_{t+s+1}^{H}}{R_{t+s}}=\sum_{a=0}^{T-1} n_{t+s}^{t+s-a} b_{t+s}^{t+s-a}$.

The no-arbitrage condition is satisfied:

$$
R_{t+s}=\alpha K^{\alpha-1}\left(Z_{t+s+1} N_{t+s+1}\right)^{1-\alpha}+1-\delta^{K} .
$$

The government budget constraint is balanced every period:

$$
T_{t+s}=R_{t+s} \frac{\sum_{a=0}^{T-1} n_{t+s-1}^{t+s-a-1} m_{t+s-1}^{t+s-a-1} b_{t+s-1}^{t+s-a-1}}{\sum_{a=0}^{T-1} n_{t+s}^{t+s-a}} .
$$

The population dynamics are internally consistent:

$$
\begin{gathered}
n_{t+s}^{t+s}=n_{t+s}, \\
n_{t+s+a}^{t+s}=\left(1-m_{t+s+a-1}^{t+s}\right) n_{t+s+a-1}^{t+s} .
\end{gathered}
$$

Note that the no-arbitrage condition holds ex ante rather than ex post. Unexpected shocks can lead returns to differ across assets, and I will elaborate these later when I define the transition dynamics.

\section{A4. No Steady State Balanced Growth Path}

An important feature of the model economy is that there is no steady state balanced growth path if the elasticity of substitution between land and structures is different from 1, unless a special condition is satisfied: the growth rate of land quantity is the same as that of structure quantity. Proposition A1 proves this feature.

Proposition A1 A steady state exists if and only if the following conditions are 
satisfied: $\rho=0$ or $g_{t}^{\mu}=\left(1-\frac{\omega}{1+\gamma}\right)\left(g_{t}^{Z}+g_{t}^{N}\right)$.

Proof: given that

$$
\frac{H_{t}}{H_{t-1}} \frac{L_{t-1}}{L_{t}}=\left(\frac{\phi\left(\frac{S_{t}}{L_{t}}\right)^{-\rho}+(1-\phi)}{\phi\left(\frac{S_{t-1}}{L_{t-1}}\right)^{-\rho}+(1-\phi)}\right)^{-\frac{1}{\rho}},
$$

the following relationship holds in a steady state balanced growth path:

$$
\left(\frac{S_{t-1}}{L_{t-1}}\right)^{-\rho} \phi\left(e^{-\rho\left(g^{H}-g^{L}\right)}-e^{-\rho\left(g^{S}-g^{L}\right)}\right)=(1-\phi)\left(1-e^{-\rho\left(g^{H}-g^{L}\right)}\right)
$$

Given that $\phi \in(0,1), 1-\phi>0$. If $g^{H} \neq g^{L}, 1-e^{-\rho\left(g^{H}-g^{L}\right)} \neq 0$ implies that $\left(\frac{S_{t-1}}{L_{t-1}}\right)^{-\rho}$ should be a constant. This is possible only if $\rho=0$ or $g^{S}=g^{L}$. The latter implies that $g^{H}=g^{L}$, which contradicts $g^{H} \neq g^{L}$. If $g^{H}=g^{L}$, $\frac{H_{t}}{L_{t}}=\left(\phi\left(\frac{S_{t}}{L_{t}}\right)^{-\rho}+(1-\phi)\right)^{-\frac{1}{\rho}}$ is a constant in the steady state, which is possible only if $g^{S}=g^{L}$. Now, I show that $g^{S}=g^{L}$ implies that $g_{t}^{\mu}=\left(1-\frac{\omega}{1+\gamma}\right)\left(g_{t}^{Z}+g_{t}^{N}\right)$.

The main challenge here is to deal with the heterogeneity of household in age, which complicates the relationship between aggregate variables. Before analyzing the implications of the heterogeneity, I first use the optimality conditions of the representative housing service producer and the representative land developer to connect the growth of structure prices $g_{t}^{\mu}$ with aggregate demand for housing services $g_{t}^{d}+g_{t}^{H}$.

The FOCs of the representative housing services producer give: $g_{t}^{P^{L}}+g_{t}^{L}=$ $g_{t}^{d}+g_{t}^{H}$ and $g_{t}^{P^{S}}+g_{t}^{S}=g_{t}^{d}+g_{t}^{H}$.

The FOC of the representative land developer gives: $\omega p_{t}^{L} A_{t}^{L}\left(I_{t}^{L}\right)^{\omega-1}=1$, which implies that: $g_{t}^{P^{L}}+g_{t}^{A^{L}}+(\omega-1) g_{t}^{I^{L}}=0$. The dynamics of land quantity, $L_{t}-L_{t-1}=A_{t}^{L}\left(I_{t}^{L}\right)^{\omega}$, and $A_{t}^{L}=A^{L}\left(L_{t-1}\right)^{-\gamma}$ further imply that, $g_{t}^{L}=g_{t}^{A^{L}}+\omega g_{t}^{I^{L}}$ and $g_{t}^{A^{L}}=-\gamma g^{L}$. Combining these equations yields $g_{t}^{P^{L}}=\left(\frac{1+\gamma}{\omega}-1\right) g^{L}$, which implies that $g_{t}^{L}=\frac{\omega}{1+\gamma}\left(g_{t}^{d}+g_{t}^{H}\right)$. Since $g_{t}^{L}=g_{t}^{S}$ and $g_{t}^{P^{S}}=g_{t}^{\mu}, g_{t}^{P^{S}}+g_{t}^{S}=g_{t}^{d}+g_{t}^{H}$ yields that $g_{t}^{\mu}=\left(1-\frac{\omega}{1+\gamma}\right)\left(g_{t}^{d}+g_{t}^{H}\right)$.

In the next, I show that $g_{t}^{d}+g_{t}^{H}=g_{t}^{Z}+g_{t}^{N}$. It suffices to show that (i) the interest rate is a constant; (ii) the wage grows at the same rate as the productivity of general goods production; (iii) the government transfer grows at the same rate as the productivity of general goods.

To show (i), i.e., the interest rate is a constant, note that the first order condition (FOC) of the housing services producer with respect to land quantity yields: $-p_{t}^{L}+\frac{p_{t+1}^{L}}{R_{t+1}}=(1-\phi) d_{t}\left(\frac{S_{t}}{L_{t}}\right)^{\phi}$ and $-p_{t}^{L}\left(1-\frac{e^{g^{P^{L}}}}{R_{t+1}}\right)=(1-\phi) d_{t}\left(\frac{S_{t}}{L_{t}}\right)^{\phi}$, which implies that $e^{g^{P^{L}}}\left(1-\frac{e^{g^{P^{L}}-g^{R}}}{R_{t}}\right)=e^{g^{d}+\phi\left(g^{S}-g^{L}\right)}\left(1-\frac{e^{g^{P^{L}}}}{R_{t}}\right)$ in the steady state. If the interest rate $R_{t}$ is not a constant over time, $e^{g^{P^{L}}}\left(1-\frac{e^{g^{P^{L}}-g^{R}}}{R_{t}}\right)=e^{g^{d}+\phi\left(g^{S}-g^{L}\right)}\left(1-\frac{e^{g^{P^{L}}}}{R_{t}}\right)$ 
holds only if $g^{P^{L}}=g^{d}+\phi\left(g^{S}-g^{L}\right)$ and $g^{P^{L}}+\left(g^{P^{L}}-g^{R}\right)=g^{d}+\phi\left(g^{S}-g^{L}\right)+g^{P^{L}}$, which together imply that $g^{R}=0$ and create a contradiction.

To show (ii), i.e, the wage grows at the same rate as the productivity of general goods, note that the FOCs of the representative general goods producer with respect to capital and labor yield that: $\alpha\left(\frac{K_{t}}{Z_{t} N_{t}}\right)^{\alpha-1}=R_{t}+\delta^{K}-1$ and $(1-$ $\alpha) Z_{t}\left(\frac{K_{t}}{Z_{t} N_{t}}\right)^{\alpha}=w_{t}$. With a constant interest rate $R_{t}$, these FOCs can hold only if $w_{t}$ grows at the same as $Z_{t}$.

To show (iii), i.e., the government transfer grows at the same rate as the productivity of general goods, note that equal transfers to households in a given period and constant growth rates of aggregate transfer and population size imply that the transfer to an individual household grows at a constant rate. I need to show that this constant rate is the same as the productivity growth rate. For the question not to be trivial, I consider the case the government transfer received by individual households is strictly positive.

Households' problems can be transformed as

$$
\begin{array}{r}
\max _{\left\{c_{t+a}^{t}, h_{t+a}^{t}, b^{t} t+a\right\}_{a=0, \ldots, T-1}} \sum_{a=0}^{T-1} \beta^{a} \prod_{j=0}^{a-1}\left(1-m_{t+j}^{t}\right) u\left(\frac{c_{t+a}^{t}}{Z_{t+a}}, \frac{d_{t+a}^{t} h_{t+a}^{t}}{Z_{t+a}} ; \phi_{t+a}^{t}\right) \\
\text { s.t. } \frac{c_{t+a}^{t}}{Z_{t+a}}+\frac{d_{t+a}^{t} h_{t+a}^{t}}{Z_{t+a}}+\frac{b_{t+a}^{t}}{Z_{t+a}}=\frac{R}{g^{A}} \frac{b_{t+a-1}^{t}}{Z_{t+a-1}}+\frac{w_{t+a}}{Z_{t+a}} l^{a}+\frac{T_{t+a}}{Z_{t+a}} \\
b_{t-1}^{t}=0, b_{t+T-1}^{t} \geq 0
\end{array}
$$

As $w_{t}$ and $Z_{t}$ grow at the same rate, $\frac{w_{t+a}}{Z_{t+a}}$ is a constant, denoted as $\bar{w}$. The consumption of individual households has the form: $\frac{c_{t+a}^{t}}{Z_{t+a}}=f\left(\bar{w}, \frac{R}{g^{Z}}, \frac{T_{t+a}}{Z_{t+a}}, g^{T}-\right.$ $\left.g^{Z}, a\right)$. Accordingly, the aggregate consumption satisfies:

$$
\sum_{a=0}^{T-1} n_{t}^{t-a} c_{t}^{t-a}=\sum_{a=0}^{T-1} n_{t}^{t-a} Z_{t} f\left(\bar{w}, \frac{R}{g^{Z}}, \frac{T_{t+a}}{Z_{t+a}}, g^{T}-g^{Z}, a\right)
$$

The aggregate consumption grows at a constant rate $g^{C}$ in the steady state, which implies

$$
\begin{array}{r}
\sum_{a=0}^{T-1} n_{t+m}^{t+m-a} Z_{t+m} f\left(\bar{w}, \frac{R}{g^{Z}}, \frac{T_{t+m+a}}{Z_{t+m+a}}, g^{T}-g^{Z}, a\right) \\
=e^{g^{C}} \sum_{a=0}^{T-1} n_{t+m-1}^{t+m-a-1} Z_{t+m-1} f\left(\bar{w}, \frac{R}{g^{Z}}, \frac{T_{t+m+a-1}}{Z_{t+m+a-1}}, g^{T}-g^{Z}, a\right),
\end{array}
$$

where $g^{T}$ is the growth rate of the government transfer received by individual households, and $g^{Z}$ is the growth rate of aggregate productivity.

As $n_{t+m}^{t+m-a}$ and $Z_{t+m}$ both grow at constant rates $g^{n}$ and $g^{Z}$ when $m$ increases, 
we can transform equation (A4) and obtain

$$
\begin{array}{r}
\sum_{a=0}^{T-1} n_{t}^{t-a} Z_{t} f\left(\bar{w}, \frac{R}{g^{Z}}, \frac{T_{t+m+a}}{Z_{t+m+a}}, g^{T}-g^{Z}, a\right) \\
=e^{g^{C}-g^{n}-g^{Z}} \sum_{a=0}^{T-1} n_{t}^{t-a} Z_{t} f\left(\bar{w}, \frac{R}{g^{Z}}, \frac{T_{t+m+a-1}}{Z_{t+m+a-1}}, g^{T}-g^{Z}, a\right),
\end{array}
$$

which further implies that

$$
\begin{array}{r}
\lim _{m->\infty} \frac{\sum_{a=0}^{T-1} n_{t}^{t-a} Z_{t} f\left(\bar{w}, \frac{R}{g^{Z}}, \frac{T_{t+m+a}}{Z_{t+m+a}}, g^{T}-g^{Z}, a\right)}{\sum_{a=0}^{T-1} n_{t}^{t-a} Z_{t} f\left(\bar{w}, \frac{R}{g^{Z}}, \frac{T_{t+m+a-1}}{Z_{t+m+a-1}}, g^{T}-g^{Z}, a\right)} \\
=\frac{\sum_{a=0}^{T-1} n_{t}^{t-a} Z_{t} f\left(\bar{w}, \frac{R}{g^{Z}}, \frac{T_{t+a}}{Z_{t+a}}, g^{T}-g^{Z}, a\right)}{\sum_{a=0}^{T-1} n_{t}^{t-a} Z_{t} f\left(\bar{w}, \frac{R}{g^{A}}, \frac{T_{t+a-1}}{Z_{t+a-1}}, g^{T}-g^{Z}, a\right)},
\end{array}
$$

for all $m>0$. Now I prove that whether $g^{T}>g^{Z}$ or $g^{T}<g^{Z}$, there are contradictions.

If $g^{T}>g^{Z}$

$$
\begin{aligned}
\lim _{m->\infty} & \frac{\sum_{a=0}^{T-1} n_{t}^{t-a} Z_{t} f\left(\bar{w}, \frac{R}{g^{Z}}, \frac{T_{t+m+a}}{Z_{t+m+a}}, g^{T}-g^{Z}, a\right)}{\sum_{a=0}^{T-1} n_{t}^{t-a} Z_{t} f\left(\bar{w}, \frac{R}{g^{Z}}, \frac{T_{t+m+a-1}}{Z_{t+m+a}}, g^{T}-g^{Z}, a\right)} \\
=e^{g^{T}+g^{Z}} & \\
> & \frac{\sum_{a=0}^{T-1} n_{t}^{t-a} Z_{t} f\left(\bar{w}, \frac{R}{g^{Z}}, \frac{T_{t+a}}{Z_{t+a}}, g^{T}-g^{Z}, a\right)}{\sum_{a=0}^{T-1} n_{t}^{t-a} Z_{t} f\left(\bar{w}, \frac{R}{g^{Z}}, \frac{T_{t+a-1}}{Z_{t+a-1}}, g^{T}-g^{Z}, a\right)} .
\end{aligned}
$$

Then the strict inequality (A6) contradicts the equality (A5). If $g^{T}<g^{A}$

$$
\begin{aligned}
\lim _{m->\infty} & \frac{\sum_{a=0}^{T-1} n_{t}^{t-a} Z_{t} f\left(\bar{w}, \frac{R}{g^{Z}}, \frac{T_{t+m+a}}{Z_{t+m+a}}, g^{T}-g^{Z}, a\right)}{\sum_{a=0}^{T-1} n_{t}^{t-a} Z_{t} f\left(\bar{w}, \frac{R}{g^{Z}}, \frac{T_{t+m+a-1}}{Z_{t+m+a}}, g^{T}-g^{Z}, a\right)} \\
= & 1 \\
> & \frac{\sum_{a=0}^{T-1} n_{t}^{t-a} Z_{t} f\left(\bar{w}, \frac{R}{g^{Z}}, \frac{T_{t+a}}{Z_{t+a}}, g^{T}-g^{Z}, a\right)}{\sum_{a=0}^{T-1} n_{t}^{t-a} Z_{t} f\left(\bar{w}, \frac{R}{g^{Z}}, \frac{T_{t+a-1}}{Z_{t+a-1}}, g^{T}-g^{Z}, a\right)} .
\end{aligned}
$$

Then the strict inequality (A7) contradicts the equality (A5). Q.E.D. 


\section{A5. Definition of transition dynamics}

The calibrated parameters and the growth of productivity and demographic structures imply that the United States economy was not on a steady state balanced growth path between 2000 and 2015, once we consider housing dynamics. Then, I study the housing cycle between 2000 and 2015 by assuming that housingrelated shocks during this period, instead of leading to fluctuations around a certain steady state balanced growth path, made the economy change from one transition dynamics to another.

I make the following assumptions to study such transition dynamics:

(i) the model economy is in an initial steady state in 1950;

(ii) it reaches a long-run steady state in 2250;

(iii) the model economy receives a shock in 1950 that leads it to embark on a transition dynamics, and is hit by multiple shocks that have zero probability ex ante between 2000 and 2015;

(iv) there are no other shocks between 1950 and 2000 or after 2015 (except for a change far away in time from 2000-15 that makes the economy converge to the long-run steady state.)

Regarding the nature of the shocks received by the model economy between 2000 and 2015, I consider four types of shocks in the baseline: productivity shocks, housing demand shocks, belief shocks, and shocks to structure prices. In a robustness test, I replace belief shocks about housing preference of future generations with belief shocks about long-term productivity growth.

Given that agents have perfect foresight, all assets pay the same return. Consequently, the portfolio choice problem of households is undetermined ex ante. To deal with the issue that shocks lead to a divergence in return across asset classes ex post, I specify a simple rule later to determine household portfolio composition, and my results should not be sensitive to choosing a different rule.

The rest of the subsection is organized into four parts: (1) the characterization of the steady state balanced growth path; (2) a simple rule about household portfolio choices; (3) the characterization of the initial steady state; (4) the characterization of the long-run steady state; (5) the characterization of the transition dynamics between 1950 and 2250 .

Part 1. STEAdy State Balanced GRowth PATH

The relationships between transformed macroeconomic variables in a steady state balanced growth path are characterized by Proposition A2 and A3.

Proposition A2 In any steady state balanced growth path, the growth rates 
of macroeconomic variables satisfy the following relationships:

$$
\begin{aligned}
g_{t}^{H} & =\phi g_{t}^{S}+(1-\phi) g_{t}^{L}, \\
g_{t}^{d} & =g_{t}^{Z}+g_{t}^{N}-g_{t}^{H} \\
g_{t}^{L} & =\frac{\omega}{1+\gamma} g_{t}^{A}+g_{t}^{N} \\
g^{P_{t}^{L}} & =\left(1-\frac{\omega}{1+\gamma}\right)\left(g_{t}^{A}+g_{t}^{N}\right), \\
g_{t}^{S} & =g_{t}^{A}+g_{t}^{N}-g_{t}^{\mu} \\
g_{t}^{K} & =g_{t}^{A}+g_{t}^{N} \\
g_{t}^{w} & =g_{t}^{A}
\end{aligned}
$$

Proof: See the proof of proposition A1.

Define $R^{s}=R_{t}, w^{s}=\frac{w_{t}}{Z_{t}}, T^{s}=\frac{T_{t}}{Z_{t}}, h^{a, s}=\frac{d_{t} h_{t}^{t-a+1}}{Z_{t}}, b^{a, s}=\frac{b_{t}^{t-a+1}}{Z_{t}}, c^{a, s}=$ $\frac{c_{t}^{t-a+1}}{Z_{t}}, n^{a, s}=\frac{n_{t}^{t-a+1}}{\sum_{a=1, \ldots, T} n_{t}^{t-a+1}}, e^{s}=\frac{\sum_{a=1, \ldots, T} n_{t}^{t-a+1} e^{a}}{\sum_{a=1, \ldots, T} n_{t}^{t-a+1}}, H^{s}=\frac{d_{t} \sum_{a=1, \ldots, T} n_{t}^{t-a+1} h_{t}^{t-a+1}}{Z_{t} \sum_{a=1, \ldots, T} n_{t}^{t-a+1} e^{a}}$ $X^{s}=\frac{X_{t} n_{t}^{t-a+1} e^{a}}{A_{t} \sum_{a=1, \ldots, T}}$ for $X \in\left\{K, L, S, I^{L}, I^{S}, V^{H}, V^{L}\right\}$ in a steady state balanced growth path.

Proposition A3 The transformed variables $\left\{R^{s}, w^{s}, T^{s}, h^{a, s}, b^{a, s}, c^{a, s}, n^{a, s}, e^{s}, H^{s}\right.$, $\left.K^{s}, L^{s}, S^{s}, I^{L, s}, I^{S, s}, V^{H, s}, V^{L, s}\right\}$ satisfy the following relationships in a steady state balanced growth path:

$$
\begin{aligned}
1-\frac{1-\delta^{K}}{R^{s}} & =\alpha\left(K^{s}\right)^{\alpha-1} \\
w^{s} & =(1-\alpha)\left(K^{s}\right)^{\alpha} \\
n^{a, s} & =\frac{\prod_{i=0}^{a-1} M^{i} e^{-i g^{n}}}{\sum_{k=0}^{T-1}\left(\prod_{j=0}^{k-1} M^{j} e^{-j g^{n}}\right)} \\
e^{s} & =\frac{\sum_{k=0}^{T-1}\left(\prod_{j=0}^{m-1} M^{j} e^{-j g^{n}} e^{k}\right)}{\sum_{k=0}^{T-1}\left(\prod_{j=0}^{m-1} M^{j} e^{-j g^{n}}\right)} \\
H^{s} & =\frac{\sum_{k=0}^{T-1} n^{a, s} h^{a, s}}{e^{s}} \\
T^{s} & =\sum_{k=0}^{T-1} n^{k, s} M^{k} R^{s} b^{k, s} e^{-\left(g^{A}+g^{N}\right)} \\
\frac{P_{t}^{L} L_{t}}{Z_{t} N_{t}} & =\frac{1-\phi}{1-\frac{e^{g^{P}}}{R^{s}}} H^{s}
\end{aligned}
$$




$$
\begin{aligned}
& \frac{P_{t}^{S} S_{t}}{Z_{t} N_{t}}=\frac{\phi}{1-\frac{\left(1-\delta^{S}\right) e^{P^{S}}}{R^{s}}} H^{s} \\
& V^{H, s}=\left(\frac{1-\phi}{1-\frac{e^{g^{P L}}}{R^{s}}} \frac{1}{e^{g^{L}}}+\frac{\phi\left(1-\delta^{S}\right)}{1-\frac{\left(1-\delta^{S}\right) e^{g^{S}}}{R^{s}}} \frac{1}{e^{g^{S}}}\right) H^{s} \\
& V^{L, s}=\left(\frac{1-\phi}{1-\frac{e^{g^{P}}}{R^{s}}} \frac{1}{1-\frac{e^{g^{A}+g^{N}}}{R^{s}}} H^{s}(1-\omega)\left(1-\frac{1}{e^{g^{L}}}\right)\right. \\
& \frac{\sum_{k=0}^{T-1} n^{k, s} b^{k, s}}{e^{s}}=e^{g^{A}+g^{N}} \frac{V^{H, s}+V^{L, s}}{R^{s}}+\frac{K^{s}}{R^{s}} \\
& \max _{\left\{c^{a, s}, h^{a, s}, b^{a, s}\right\}_{a=0, \ldots, T-1}} \sum_{a=0}^{T-1} \beta^{a} \prod_{j=0}^{a-1}\left(1-M^{j}\right) u\left(c^{a, s}, h^{a, s} ; \phi^{s}\right) \\
& \text { s.t. } c^{a, s}+h^{a, s}+b^{a, s}=R^{s} e^{-g^{A}} b^{a-1, s s}+w^{s} e^{a}+T^{s} \\
& b^{T-1, s} \geq 0
\end{aligned}
$$

Proof: These equations can be found in the proof of proposition A1 and through algebra, be derived from market clearing conditions.

\section{Part 2. Household portfolio Choices}

To make it easier to describe the rule, I define that a household owns the home in which he or she lives, which provides $h_{t}$ housing services, if the household owns at least $\frac{h_{t}}{H_{t}}$ fraction of the total share of representative housing service producer, where $H_{t}$ is the housing services in the aggregate economy. The value of the home that provides the housing services to the household is denoted as $v_{t}^{H}\left(h_{t}\right)$, which satisfies

$$
v_{t}^{H}\left(h_{t}\right)=\frac{h_{t}}{H_{t}} V_{t}^{H} .
$$

There are three aspects of the rule.

(1) If the net worth of a household aged $a$ in period $t$, denoted earlier as $b_{t}^{t-a}$, exceeds $20 \%$ of $v_{t}^{H}\left(h_{t}^{t-a}\right)$, he is a homeowner.

(2) If a household is a renter and the net worth is negative or if the household is a homeowner and the net worth minus $v_{t}^{H}\left(h_{t}\right)$ is negative, the household does not invest in any of the following types of assets: (i) loans lent to households, (ii) the properties leased to renters, and (iii) the physical capital, and (iv) the shares of the mutual fund owning land developers. In other words, the household only borrows from other households.

(3) Renters who have positive net worth and homeowners who do not only borrow from other households (i.e. whose net worth exceeds the value of their home) have the same portfolio.

The rule implies four types of households in terms of portfolio composition: (i) renters who only borrow and do not invest in any assets; (ii) homeowners who 
only borrow; (iii) renters who invest in assets; and (iv) homeowners who invest in assets other than the home owned.

To characterize the portfolio of individual households and to show the evolution of aggregate variables, define two dummies indicating whether a household is a homeowner and whether a household invests in non-housing assets, $I_{t}^{\text {own }, a}$ and $I_{t}^{\mathrm{inv}, a}$, as:

$$
\begin{aligned}
I_{t}^{\text {own }, a} & =1 \text { if and only if } b_{t}^{t-a}>0.2 \frac{h_{t}^{t-a}}{H_{t}} V_{t}^{H} ; \\
I_{t}^{\text {inv }, a} & =1 \text { if and only if one of the following two conditions hold: } \\
& \text { (i) } I_{t}^{\text {own }, a}=1 \text { and } b_{t}^{t-a}>\frac{h_{t}^{t-a}}{H_{t}} V_{t}^{H} ; \\
& \text { (ii) } I_{t}^{\text {own }, a}=0 \text { and } b_{t}^{t-a}>0 .
\end{aligned}
$$

The aggregate borrowing of households $B_{t}$, the aggregate wealth of households who invest in non-housing assets $N W_{t}^{I n v}$, the aggregate value of houses owned by households who invest in non-housing assets $V_{t}^{H, I n v}$, the aggregate value of houses owned by all homeowners $V^{H, o w n}$, the aggregate value of houses rented $V_{t}^{H, r e n t}$ satisfy the following equations:

$$
\begin{aligned}
B_{t} & =\sum_{a=0}^{T-1}\left\{\left(b_{t}^{t-a}-\frac{h_{t}^{t-a}}{H_{t}} V_{t}^{H}\right) I_{t}^{\mathrm{own}, a}\left(1-I_{t}^{\mathrm{inv}, a}\right)\right. \\
& \left.+b_{t}^{t-a}\left(1-I_{t}^{\mathrm{own}, a}\right)\left(1-I_{t}^{\mathrm{inv}, a}\right)\right\} \\
N W_{t}^{\text {Inv }} & =\sum_{a=0}^{T-1} b_{t}^{t-a} I_{t}^{\mathrm{own}, a} I_{t}^{\mathrm{inv}, a}+b_{t}^{t-a}\left(1-I^{\mathrm{own}, a, t}\right) I_{t}^{\mathrm{inv}, a} \\
V_{t}^{H, I n v} & =\sum_{a=0}^{T-1} \frac{h_{t}^{t-a}}{H_{t}} V_{t}^{H} I_{t}^{\mathrm{own}, a} I_{t}^{\mathrm{inv}, a} \\
V_{t}^{H, \text { own }} & =\sum_{a=0}^{T-1} \frac{h_{t}^{t-a}}{H_{t}} V_{t}^{H} I_{t}^{\mathrm{own}, a}, \\
V_{t}^{H, \text { rent }} & =\sum_{a=0}^{T-1} \frac{h_{t}^{t-a}}{H_{t}} V_{t}^{H}\left(1-I_{t}^{\mathrm{own}, a}\right) .
\end{aligned}
$$

Let $v_{t}^{H, t-a}, v_{t}^{L, t-a}, v_{t}^{K, t-a}$, and $v_{t}^{B, t-a}$ be the value of the shares of the housing service producer owned by, the value of the shares of the mutual fund (owning all land developers) owned by, the value of physical capital stock owned by, and the net position in loan for a household born in period $t-a$ in period $t$. Define four ratios $\theta_{t}^{V H}, \theta_{t}^{V L}, \theta_{t}^{K}$, and $\theta_{t}^{B}$ as: 


$$
\begin{aligned}
\theta_{t}^{V H} & =\frac{V_{t}^{H, \text { rent }}}{V_{t}^{H, \text { rent }}+V_{t}^{L}+K_{t+1}-B_{t}}, \\
\theta_{t}^{V L} & =\frac{V_{t}^{L}}{V_{t}^{H, \text { rent }}+V_{t}^{L}+K_{t+1}-B_{t}}, \\
\theta_{t}^{K} & =\frac{K_{t+1}}{V_{t}^{H, \text { rent }}+V_{t}^{L}+K_{t+1}-B_{t}}, \\
\theta_{t}^{B} & =\frac{-B_{t}}{V_{t}^{H, \text { rent }}+V_{t}^{L}+K_{t+1}-B_{t}} .
\end{aligned}
$$

The portfolio choice of a household born in period $t-a$ in period $t$ satisfies the following equations:

$$
\begin{aligned}
v_{t}^{H, t-a} & =I^{\mathrm{own}, a, t} I^{\mathrm{inv}, a, t}\left(\theta_{t}^{V H}\left(b_{t}^{t-a}-v^{H}\left(h_{t}\right)\right) v^{H}\left(h_{t}\right)\right)+I^{\mathrm{own}, a, t}\left(1-I^{\mathrm{inv}, a, t}\right) v^{H}\left(h_{t}\right) \\
& +\left(1-I^{\mathrm{own}, a, t}\right) I^{\mathrm{inv}, a, t} \theta_{t}^{V H} b_{t}^{t-a} \\
v_{t}^{L, t-a} & =I^{\mathrm{own}, a, t} I^{\mathrm{inv}, a, t} \theta_{t}^{V L}\left(b_{t}^{t-a}-v^{H}\left(h_{t}\right)\right)+\left(1-I^{\mathrm{own}, a, t}\right) I^{\mathrm{inv}, a, t} \theta_{t}^{V L} b_{t}^{t-a} \\
v_{t}^{K, t-a} & =I^{\mathrm{own}, a, t} I^{\mathrm{inv}, a, t} \theta_{t}^{K}\left(b_{t}^{t-a}-v^{H}\left(h_{t}\right)\right)+\left(1-I^{\mathrm{own}, a, t}\right) I^{\mathrm{inv}, a, t} \theta_{t}^{K} b_{t}^{t-a} \\
v_{t}^{B, t-a} & =I^{\mathrm{own}, a, t} I^{\mathrm{inv}, a, t} \theta_{t}^{B}\left(b_{t}^{t-a}-v^{H}\left(h_{t}\right)\right)+\left(1-I^{\mathrm{own}, a, t}\right) I^{\mathrm{inv}, a, t} \theta_{t}^{B} b_{t}^{t-a} \\
& +I^{\mathrm{own}, a, t}\left(1-I^{\mathrm{inv}, a, t}\right)\left(b_{t}^{t-a}-v_{t}^{H, t-a}\right)+\left(1-I^{\mathrm{own}, a, t}\right)\left(1-I^{\mathrm{inv}, a, t}\right) b_{t}^{t-a}
\end{aligned}
$$

PART 3. The Initial STEADy STATE

The mortality rate by age group in the initial steady state is chosen to be equal to the average of its data counterpart between 1900 and 1949. Using the data from the centers of disease control and prevention (CDC), I get the mortgage rate by 5 year age group in the initial steady state as $\{0.72 \%, 0.76 \%, 0.93 \%, 1.32 \%, 2.09 \%, 3.20 \%$, $5.03 \%, 7.26 \%, 10.61 \%, 15.10 \%, 22.08 \%, 32.13 \%, 44.49 \%, 59.37 \%, 72.73 \%, 100 \%$, which are further interpolated linearly to get the mortality rate by 1-year age group.

The population growth rate is chosen as the geometric average of population growth rate between 1900 and 1949, based on the data from the the United States census bureau, which is equal to $1.018 \%$.

The growth rate of the real price of structure is chosen to be the average of its data counterpart between 1930 and 1950 and is equal to $1.634 \%$.

The growth rate of labor productivity is chosen to be the average of its data counterpart between 1950 and 2015 and is equal to $1.99 \%$. 
PART 4. THE LONG-RUN STEAdy STATE

The demographic structure in the long-run steady state is determined based on the medium fertility variant in the 2015 revision of the World Population Prospects. The mortality rates come from the life table and its values are chosen to be the projected mortality rates in 2100 , and the mortality rate by 5 -year age group is $\{0.08 \%, 0.09 \%, 0.11 \%, 0.14 \%, 0.22 \%, 0.36 \%, 0.57 \%, 0.88 \%, 1.32 \%, 2.17 \%, 3.77 \%$, $6.76 \%, 12.63 \%, 23.34 \%, 39.81 \%, 100 \%$. I do linear interpolation to get the values for 1-year age groups.

The population growth rate is chosen to be the geometric average of the projected numbers between 2050 and 2095, which is equal to $0.122 \%$.

The growth rate of real structure prices is chosen to be the average of their counterparts between 1950 and 2015, which is $0.674 \%$ respectively.

The growth rate of productivity is chosen such that the relationship $g_{t}^{\mu}=$ $\left(1-\frac{\omega}{1+\gamma}\right)\left(g_{t}^{Z}+g_{t}^{N}\right)$ holds and is equal to $0.7 \%$.

PART 5. THE TRANSITION DYNAMICS BETWEEN 1950 AND 2250

The demographic structure during the transition dynamics is determined based on the estimates of and the forecasts in the medium fertility variant in the 2015 revision of the World Population Prospects. The mortality rates between 1950 and 2015 are chosen to be the estimated values, and those between 2015 and 2100 the forecast values. The mortality rates between 2100 and 2250 are chosen to be the same as forecast values of 2100 .

The growth rates of productivity and real structure price are chosen to be the same as those in the long-run steady state and are $1.99 \%$ and $0.647 \%$ respectively, except that after 2200 , the productivity growth rate declines to $0.7 \%$ (such that the relationship $g_{t}^{\mu}=\left(1-\frac{\omega}{1+\gamma}\right)\left(g_{t}^{Z}+g_{t}^{N}\right)$ holds $)$.

After the decline in the productivity growth rate, the economy converges to the long-run steady state rapidly.

\section{A6. Algorithm to compute transition dynamics}

To solve the perfect foresight equilibrium, the algorithm consists of an outer loop, which solves $\left(T_{t}\right)_{t=1950, \ldots, T^{\text {Long run }}}$ such that the government budget constraint is satisfied in every period from 1950 to $T^{\text {Long run }}$, and an inner loop, which solves $\left(\frac{S_{t}}{L_{t}}, R_{t}\right)_{t=1950, \ldots, T^{\text {Long run }}}$ from market clearing conditions of the market for developed land and that for funds. Such an algorithm can also be applied to calculating a new transition dynamics in response to a shock.

The rest of this subsection consists of two parts. In the first part, I show how $\left(\frac{S_{t}}{L_{t}}, R_{t}\right)_{t=1950, \ldots, T^{\text {Long run }}}$ can be solved, taking $\left(T_{t}, Z_{t}, P_{t}^{S}\right)_{t=1950, \ldots, T^{\text {Long run }}}$ as

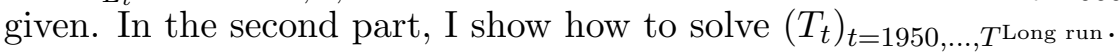


PART 1. SOLVE $\frac{S_{t}}{L_{t}}$ AND $R_{t}$

First of all, note that $\left(w_{t}, d_{t}, P_{t}^{L}\right)_{t=1950, \ldots, T^{\text {Long run }}}$ are functions of $\left(T_{t}, \frac{S_{t}}{L_{t}}, R_{t}\right.$, $\left.Z_{t}, P_{t}^{S}\right)_{t=1950, \ldots, T^{\text {Long run }}}$, based on the first order conditions of the representative general goods producer and the representative housing service producer. In particular,

$$
\begin{aligned}
w_{t} & =(1-\alpha) Z_{t}\left(\frac{R_{t}-\left(1-\delta^{K}\right)}{\alpha}\right)^{\frac{\alpha}{\alpha-1}} \\
d_{t}^{H} & =\left(\frac{P_{t}^{S}-\left(1-\delta^{S}\right) P_{t+1}^{S}}{\phi}\right)\left(\phi+(1-\phi)\left(\frac{S_{t}}{L_{t}}\right)^{\rho}\right)^{1+\frac{1}{\rho}}, \\
P_{t}^{L} & =\sum_{j=0, \ldots, \infty} \frac{1}{\prod_{s=t}^{t+j-1} R_{s}} \frac{1-\phi}{\phi}\left(\frac{S_{t+j}}{L_{t+j}}\right)^{1+\rho}\left(P_{t+j}^{S}-\left(1-\delta^{S}\right) \frac{P_{t+j+1}^{S}}{R_{t+j}}\right) .
\end{aligned}
$$

By definition of the long-run steady state, $R_{t}=R_{t-1}, \frac{S_{t}}{L_{t}}=\frac{S_{t-1}}{L_{t-1}} e^{g^{S, L R}-g^{L, L R}}$ for $t>T^{\text {Long run }}$, where $g^{S, L R}$ and $g^{L, L R}$ are solved based on proposition A.2.

Given the prices $\left(w_{t}+s, d_{t}+s, R_{t}+s\right)_{s=0, \ldots, \infty}$ and the government transfer $T_{t}$, the aggregate housing services can be computed from individual households' optimal choices of housing services and, combined with $\frac{S_{t}}{L_{t}}$ and the aggregate housing service production function, yield the demand for developed land. Formally, we have

$$
L_{t}^{D}=\frac{\sum_{a=0}^{T-1} h_{t}^{t-a}\left(\left\{w_{t}, d_{t}, R_{t}, P_{t}^{L}, P_{t}^{S}\right\}_{t=1950, \ldots, \infty}, \Omega_{1950}\right)}{\left\{\phi\left(\frac{S_{t}}{L_{t}}\right)^{1-\frac{1}{\rho}}+(1-\phi)\right\}^{\frac{\rho}{\rho-1}}},
$$

where $\Omega_{1950}$ is the relevant information in the initial steady state in 1950 .

The supply of developed land is static, and only depends on the aggregate land in the previous period and the current land price. Therefore, we can solve $\left\{L_{t}^{S}\right\}_{t=1950, \ldots, 2250}$ iteratively as a function of $\left\{P_{t}^{L}\right\}_{t=1950, \ldots, \infty}$ and $L_{1949}$, where $L_{1949}$ is the aggregate land quantity in 1949 and can be calculated based on the assumptions about the initial steady state. With these calculations, we have inputs for 301 equations: $L_{t}^{D}=L_{t}^{S}$, for $t=1950, \ldots, 2250$.

The market clearing conditions of the funding market between 1950 and 2250 give another 301 equations. Together 602 equations allow us to solve 602 unknowns $-\left\{\frac{S_{t}}{L_{t}}, R_{t}\right\}_{t=1950, \ldots, 2250 \text {. }}$

It can be extremely time consuming to do the exercises defined in the text, given that (i) 602 equations are solved just for one iteration in the inner loop; and (ii) to set up the 602 equations, I need to solve 301 generations' optimal choice problem, with each living for 80 periods $(20$ - 99). Furthermore, to understand the housing cycle between 2000 and 2015, I need to determine the shock size in each year such that the model outputs can match the data targets defined in the text.

To make the computation tractable, I assume that the elasticity of inter-temporal 
substitution (EIS) is equal to 1 . This choice allows me to choose only 2 points on a grid to compute optimal household choices, as the policy functions are linear in wealth. Having a larger number of grids will also substantially slow the computation.

Moreover, I use a revised Broyden method, which stops the codes after a certain number of iterations and resume from the place with the best solution. I find that this design substantially speeds up the computation as well.

\section{Part 2. Solve $T_{t}$}

Once we have the optimal household choices, it is easy to derive the total net worth of households who pass away at the end of the previous period. From there, we can set up the government budget constraints to solve $\left\{T_{t}\right\}_{t=1950, \ldots, T^{L R}}$.

\section{A7. Performances of the model in explaining housing trends}

This subsection demonstrates the performance of the model in explaining housing trends.

The low land-structures substitutability is inferred from the strong positive comovement between the ratio of land value to structure value and the ratio of land price to structure price in the long run, and it also plays a critical role in other housing trends. Here, I focus on how the model performance in explaining land share dynamics collapses if the elasticity of substitution between land and structures is 1 instead of 0.248. Lian (2019) shows a critical role of low landstructures substitutability in explaining other housing trends.

Panel 2 and 3 of Figure A2 show that the model is consistent with a downward trend of the ratio of residential investment to GDP, upward trends of the land share in house value and the ratio of house value to business value-added, and long-term trends of price and quantity of house, residential land and residential

structure. Except for panel 2a, I do not have any normalization for other series in panel 2.

Panel 4 of Figure A2 demonstrates the performance of the model in matching land share dynamics, and the critical role of low land-structures substitutability in the transmission of shocks to land share. If the housing service production function is of a Cobb-Douglass form, the land share becomes much less volatile with the same set of shocks. The figure also presents an important supportive evidence for the low land-structures substitutability: if the elasticity of substitution between land and structures is 1 , the land share would be stable in the long run, which is inconsistent with the data. 
1. Population Share by Age Group, 1950 - 2075
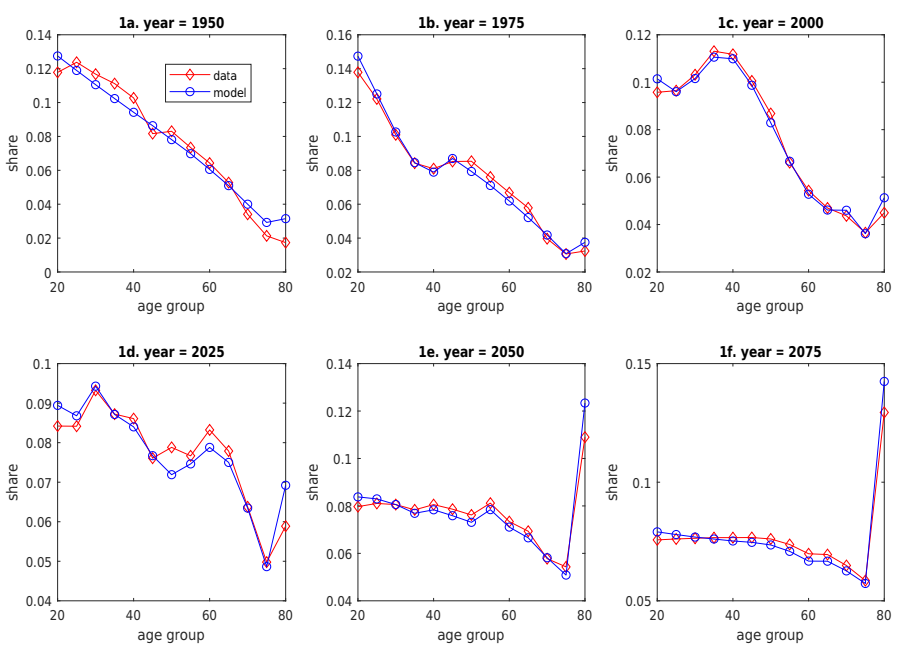

2. Key Macroeconomic Variables
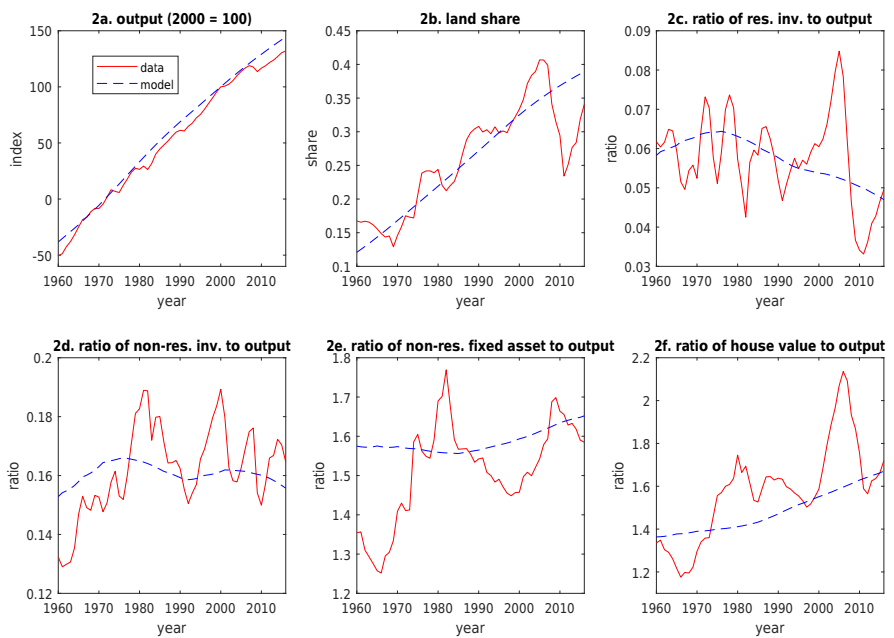
3. Price and Quantity of House, Residential Land and Residential Structures (Index, $2000=100$ )
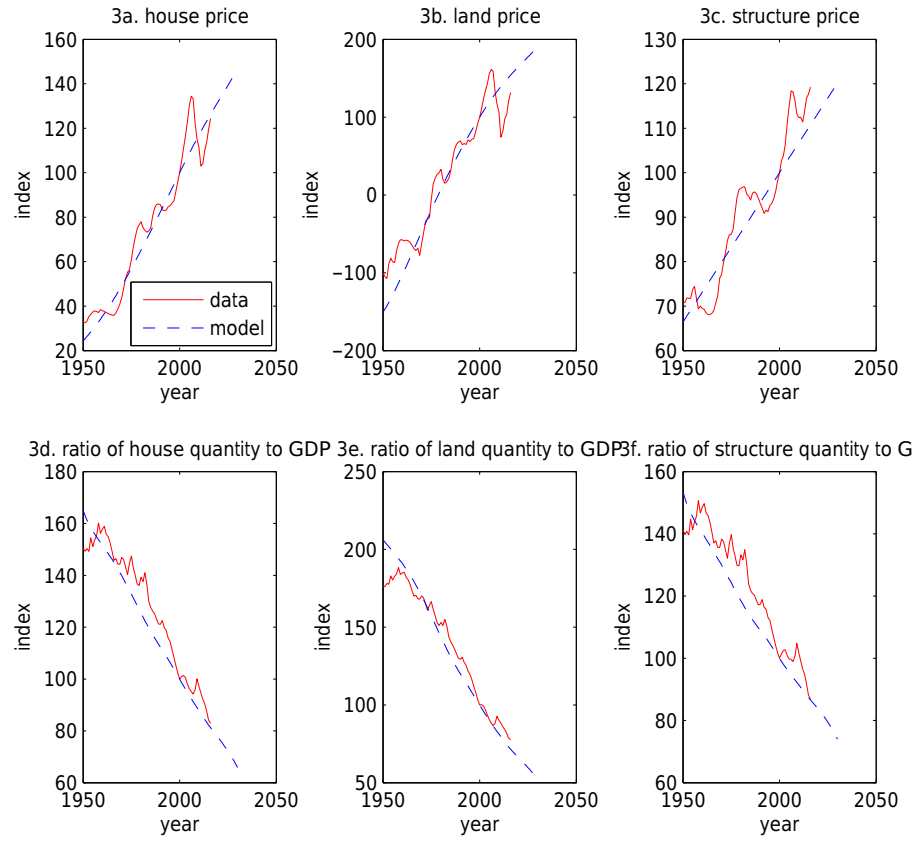

4. Land Share dynamics under different values of EOS
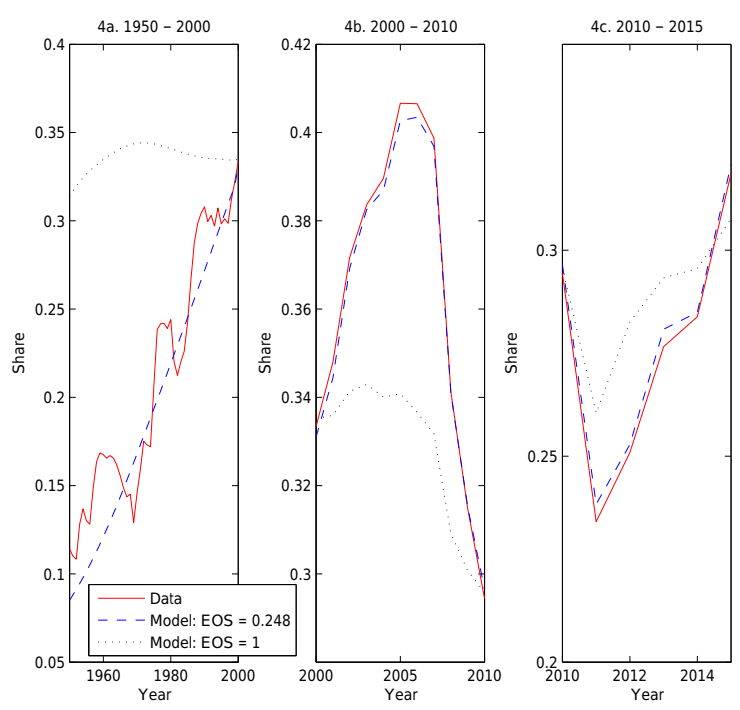

Figure A2. : Long-term performances of the model

Sources: Davis and Heathcote (2007), National Income and Product Accounts, the World Population Prospects in 2011, and the author's calculations.

Note: Figure shows that changes in demographic structure, long-term macroeconomic trends, and the price and quantity of house, residential land and residential structures in the model are all broadly consistent with their data counterparts. It also shows that low EOS is critical for the model to be consistent with land share dynamics in the data, and significantly amplifies the impact of shocks on land share. In panel 1d, 1e, and 1f, the age distributions of population are based on the medium fertility rate scenario provided by the World Population Prospects in 2011. In panel 2c, 2d, 2e and 2f, output refers to non-housing goods, and its data counterpart is the value-added of the business sector. In panel $4 \mathrm{~b}$ and $4 \mathrm{c}$, the shocks under "EOS $=1$ " are the same as the shocks under "EOS $=0.248$ ". These shocks are chosen to match the housing cycle in the 2000s, and their determination is explained in the text.

CInternational Monetary Fund. Not for Redistribution 